\title{
Development of mRNA vaccines and their prophylactic and therapeutic applications
}

\author{
Kyuri Lee ${ }^{\S}$, Minjeong Kim ${ }^{\S}$, Yunmi Seo, and Hyukjin Lee ( $\left.ه\right)$ \\ College of Pharmacy, Graduate School of Pharmaceutical Sciences, Ewha Womans University, Seoul 13760, Republic of Korea \\ ${ }^{\S}$ Kyuri Lee and Minjeong Kim contributed equally to this work.
}

\author{
Received: 14 March 2018 \\ Revised: 9 May 2018 \\ Accepted: 11 May 2018 \\ (C) Tsinghua University Press \\ and Springer-Verlag $\mathrm{GmbH}$ \\ Germany, part of Springer \\ Nature 2018

\section{KEYWORDS} \\ messenger RNA (mRNA) \\ vaccines, \\ prophylactic vaccines, \\ self-amplifying mRNA \\ vaccines, \\ therapeutic vaccine, \\ cancer immunotherapy
}

\begin{abstract}
Nucleic acid vaccines have attracted enormous attention for resolving the limitations of conventional vaccines using live attenuated viruses. Because nucleic acid vaccines can be produced rapidly in response to the emergence of new virus strains, they are more appropriate for the control of urgent epidemic and pandemic issues. In particular, messenger RNA (mRNA) vaccines have evolved as a new type of nucleic acid vaccines in accordance with their superior protein expression and a lack of mutagenesis as compared with DNA vaccines. Using mRNA vaccines, large amounts of target proteins can be expressed in immune cells for efficient immunization. For instance, antigen-specific vaccination is a feasible option involving the expression of specific antigens in antigen-presenting cells. Immunological reactions are modulated by expressing several proteins associated with stimulation or maturation of immune cells. In addition, mRNA vaccines can stimulate innate immunity through specific recognition by pattern recognition receptors. On the basis of these remarkable properties, mRNA vaccines have been used for prophylactic and therapeutic applications. This review highlights the role of mRNA vaccines as prophylactic vaccines for prevention of future infections and as therapeutic vaccines for cancer immunotherapy. In addition to the conventional type of mRNA vaccines, RNA replicons (self-amplifying mRNA vaccines) will be described.
\end{abstract}

\section{Introduction}

Historically, vaccines have been prepared as attenuated live viruses altered to reduce the virulence or as inactivated pathogens that are killed by chemical and physical methods [1-4]. These vaccines were administered to healthy people as defense against future infections (known as a prophylactic vaccine). Once an attenuated or inactivated virus is injected into the body, antigen-presenting cells (APCs) engulf the virus and present the processed viral antigens to $T$ cells $[5,6]$. In a humoral immune response, $\mathrm{T}$ cells are activated, and the activated $\mathrm{CD} 4{ }^{+} \mathrm{T}$ helper cells prime $B$ cells to develop into plasma cells, generating

Address correspondence to hyukjin@ewha.ac.kr 
antibodies, which protect the body by preventing future viral infections. In addition to prevention of a future infection, the concept of vaccines has been widened to reinforce the immune defense system to treat already existing infection or diseased states [5, 7-10]. These vaccines are known as therapeutic vaccines. Cancer immunotherapy is the largest field of therapeutic vaccines developed to boost the immune defense system of the human body [11-15]. Normally, cancer cells survive in our bodies by hiding from the immune surveillance system. Cancer vaccines facilitate immune recognition of cancer cells as abnormal cells by inducing the presentation of specific antigens via the APCs (Fig. 1). Once the antigens are expressed in APCs, $\mathrm{CD} 8^{+} \mathrm{T}$ cells recognize the presented antigen. Eventually, $\mathrm{CD}^{+} \mathrm{T}$ cells differentiate into effector cytotoxic $\mathrm{T}$ lymphocytes (CTLs) to kill cancer cells. Even though several studies have disputed the role of therapeutic vaccines and their safety, in recent decades, several researchers have successfully investigated the potential of therapeutic vaccines as cancer therapies [16-20].

Given that the role of vaccines has been established, the conventional vaccines based on infectious agents have protected millions of people from fatal infectious diseases. Nonetheless, the conventional vaccines have several limitations, which should be resolved to strengthen the vaccine system. First, administration of whole cells of bacteria as vaccines can trigger virulence and increase the risk of death in immunocompromised patients [21, 22]. Second, manufacturing methods for conventional vaccines are not adequate to control a new pandemic or epidemic outbreak [23, 24]. Because most of pandemic strains frequently undergo antigenic drift or shift to evade immune recognition, rapid and mass production of vaccines against a new strain is urgently required [23, 25]. Nevertheless, the conventional egg-based vaccine production system is tedious and not conducive to rapid production of vaccines against new strains. Thus, there is an unmet need for rapid production of effective vaccines against new pandemic outbreaks. Finally, conventional vaccines are biological products, which lose their potency at inappropriate temperature [24]. Therefore, to maintain their properties, a cold chain system is urgently necessary for the storage

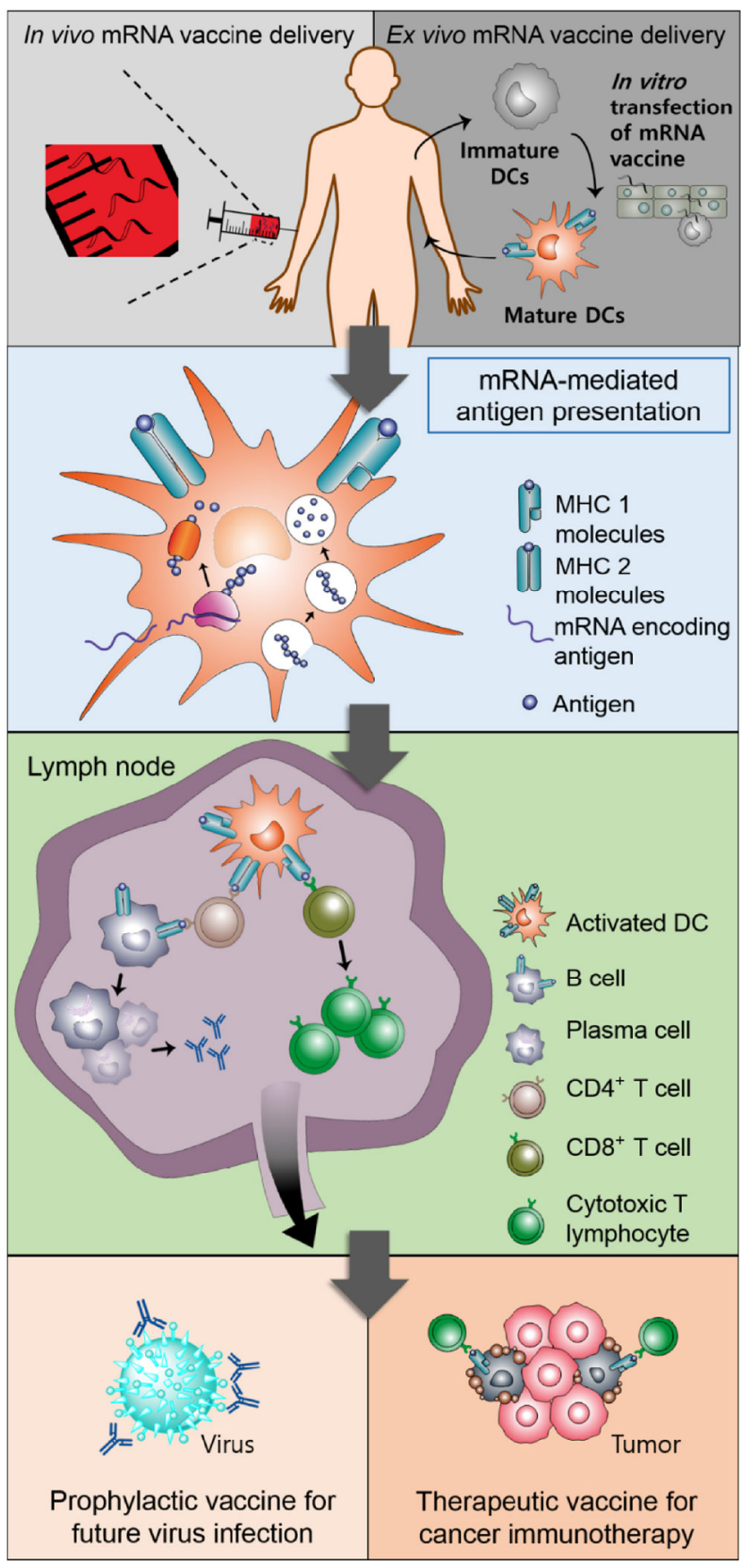

Figure 1 Schematic illustration of an mRNA vaccine-mediated immune response.

and delivery of vaccines from the time point of manufacture until the time of administration to patients. The necessity of a cold chain system is quite vexing and inconvenient, especially in many developing countries, with widespread distribution of vaccines.

In recent years, significant efforts were made to overcome the limitations of conventional vaccines $[26,27]$. 
The nucleic acid vaccine is one of the examples and has evolved over two decades after Wolff et al. demonstrated the concept of nucleic acid drugs [28]. Nucleic acids encoding specific antigens presented by APCs can induce a persistent immune response against specific antigens $[22,29,30]$. Based on this strategy, nucleic acid drugs have been utilized as a novel alternative type of vaccine relative to conventional vaccines [27]. One of the great advantages of nucleic acid vaccines over conventional vaccines is the relatively uncomplicated production system. Because of the simplicity of design and synthesis, large quantities of nucleic acid vaccines can be manufactured immediately after emergence of new pathogens, for a rapid and effective epidemic response, which is infeasible with conventional vaccines. Furthermore, nucleic acid vaccines do not require a cold chain system for transportation and storage, whereas it is a prerequisite for conventional vaccines. Thus, nucleic acid vaccines can become widespread in many developing countries that cannot afford a cold chain system.

Early in the development of nucleic acid vaccines, most researchers focused on DNA vaccines owing to their stable structure and easy-to-control properties $[22,31-33]$. On the other hand, the development of DNA vaccines has been hampered by lower immunization efficiency as compared with conventional vaccines involving whole microorganisms [33, 34]. Various adjuvants have been developed to overcome this issue and administered along with DNA vaccines for immunization [35-37]. Although several studies have shown that DNA vaccines induce an enhanced immunization effect via coadministration of adjuvants, DNA vaccines have not been practically utilized as vaccines that surpass conventional vaccines. In recent decades, messenger RNA (mRNA) vaccines emerged as powerful nucleic acid vaccines [21, 34, 38]. These vaccines have several advantages compared with DNA vaccines. First, mRNA does not require entry into the nucleus for protein expression, and can be successfully transfected into slowly dividing cells such as dendritic cells (DCs), for efficient presentation of the encoded antigens [39]. Furthermore, mRNA vaccines can trigger immunogenic responses without the need for adjuvants [40]. Despite their attractive features,
mRNA vaccines have not been widely employed as powerful nucleic acid vaccines in the past because of their unstable structure. Nonetheless, with burgeoning knowledge and insights into the design of stable and better mRNA structures, mRNA vaccines have shown a great potential as a new platform for nucleic acid vaccines in numerous recent studies [41-43].

In this concise review, mRNA vaccines developed to prevent infectious diseases (prophylactic vaccines) or treat cancer (therapeutic vaccines) will be discussed. Two types of mRNA vaccines based on a conventional type of mRNA or RNA replicons and their prophylactic applications are described. In brief, although the conventional type of mRNA is not capable of replicating itself, RNA replicons are designed to amplify themselves to enhance protein expression [44, 45]. This increase in protein expression with RNA replicons is thought to be a great advantage for effective immunization. In addition, innovative approaches to mRNA vaccines for cancer immunotherapy as therapeutic vaccines will be explained. A brief introduction to the concept of immunotherapy will also be provided with several studies showing the effectiveness of mRNA vaccines in cancer immunotherapy. Depending on the applications, various delivery strategies for mRNA vaccines have been developed. Various mRNA vaccine delivery strategies are briefly described. Finally, future perspectives of mRNA-based nucleic acid vaccines are discussed too.

\section{Prophylactic mRNA vaccines for the prevention of virus infection}

mRNA vaccines have been utilized for the prevention of future viral infections [46-48]. The mechanism of mRNA vaccine-mediated specific antigen presentation in APCs is mostly similar to that for DNA vaccines [21]. Once an mRNA vaccine enters APCs, target antigens can be expressed via translation. The target antigens encoded by the mRNA vaccines are designed to resemble the viral antigens that appear when the actual virus causes infection $[49,50]$. The endogenous antigens translated from mRNA vaccines in APCs are presented by major histocompatibility complex class I molecules (MHC class I molecules), thereby inducing a CTL response. In contrast, the exogenous antigens 
that might be produced and secreted by mRNA-treated cells are recognized by APCs and presented by MHC class II molecules. The antigen presented by the MHC class II molecules interacts with helper T cells, resulting in the induction of various cellular and humoral immune responses including B-cell-mediated antibody production. After a series of humoral immune processes, the antibodies against the antigens encoded by the mRNA vaccines are induced, thereby preventing future attacks of the antigens (Fig. 1). Even though there is controversy over the exact mechanism of mRNA vaccine-mediated antigen presentation on MHC class II molecules, many researchers have reported that mRNA vaccines can induce a successful humoral immune response by verifying the antibody titers after administration of an mRNA vaccine. Although DNA vaccines require entry into the cell nucleus after crossing two barriers (cell and nuclear membranes), mRNA vaccines act once they are delivered into the cytoplasm by crossing only a single barrier. This relatively easier delivery requirement increases the attractiveness of mRNA vaccines compared with DNA vaccines. In addition, $m R N A$ vaccines stimulate an innate immune response after binding to RNArecognizing Toll-like receptors (TLRs); this process is a great advantage for vaccination [51-53].

There are two types of mRNA vaccines: the conventional type (nonamplifying mRNA) and RNA replicon vaccines (self-amplifying mRNA vaccines: SAMs) [21, 40, $45,54]$. The conventional mRNA vaccines are mostly based on the eukaryotic mRNA structures containing a 5' cap structure [34,53]. A SAM consists of two parts: One part is for producing RNA-dependent RNA polymerase, and the other part is for encoding target antigens. The RNA-dependent RNA polymerase produced by one part of the SAM replicates the mRNA, thereby enhancing the mRNA-mediated protein expression. Thus, although conventional mRNA vaccines transiently induce antigen expression, SAM offers relatively longer and stronger expression of the encoded proteins. Because of these unique properties, the SAM has aroused interest as a strategy to improve the vaccination effect of conventional mRNA vaccines. In this section, a brief introduction to the conventional mRNA vaccines and the SAM and their applications to prophylactic vaccines will be provided.

Because the delivery issue is a critical point determining the success of nucleic acid vaccinemediated immunization, various delivery strategies have been devised to increase the antigen expression of mRNA vaccines and boost immunogenic reactions [55-57]. At the early stage of mRNA vaccines, naked mRNAs were injected intramuscularly (i.m.) without any delivery materials. They induced an antigenspecific immune reaction with a small amount of mRNA-encoded antigens. To enhance the mRNA vaccine-mediated immunization effect, much effort has been made to develop mRNA delivery materials that can protect the mRNAs from degradation and enhance the transfection into target cells. For instance, recombinant viral vector technologies have shown successful vaccination effects in various studies as delivery vehicles of mRNA vaccines [58-60]. Initially, the viral vectors received much attention because of their powerful and efficient delivery and high immune stimulation. Nevertheless, the antivector immunity induced by the viral vectors limited their further practical applications [61, 62]. To resolve this limitation, various nonviral vectors have been extensively developed [55-57]. The nonviral vectors need to be able to safely deliver an mRNA vaccine to target cells without the induction of an unwanted immune reaction. Administration of a complex of mRNA vaccines and several polymers, proteins, or lipids is an example of nonviral delivery methods. Several studies indicate that coadministration of protamine along with an mRNA vaccine facilitates not only the antigen presentation but also immune stimulation [63, 64]. In addition, various delivery strategies using lipid or polymer nanoparticles have been devised to enhance the efficacy of mRNA vaccines $[65,66]$. By formulating the mRNA vaccines into delivery carriers, the short half-life and low transfection efficiency of naked mRNAs can be greatly improved. In addition, via modulation of the physicochemical properties of delivery materials, the vaccination effect can also be affected. For instance, several studies have shown that the delivery materials in a specific size range (20-200 nm) show great accumulation in a lymph node $[67,68]$. Various other attempts have been made to deliver a vaccine specifically into target immune 
cells. According to the studies, via conjugation with various targeting materials, mRNA vaccines can be delivered specifically into target immune cells. For instance, mannose-conjugated delivery carriers are specifically delivered into macrophages or DCs expressing mannose receptors [69-71]. Several delivery strategies developed for the delivery of conventional mRNA vaccines or SAM will be presented.

\subsection{Conventional mRNA vaccines}

As mentioned above, the conventional type of mRNA vaccines is a nonamplifying mRNA, which is based on the natural eukaryotic mRNAs containing a $5^{\prime}$ cap structure, $5^{\prime}$ and $3^{\prime}$ untranslated regions (UTRs), an open reading frame (ORF), and a poly-A tail. The $5^{\prime}$ cap and poly-A tail are necessary to protect the mRNA in the cellular environment, and the functions of $5^{\prime}$ and $3^{\prime}$ UTRs are mostly related to the mRNA stability and translation profile [72, 73]. This conventional mRNA vaccine can be simply produced via in vitro transcription technique using DNA vectors carrying a T7 or SP6 promotor [73]. Because abundant antigen expression inside APCs is critical for successful vaccination, various efforts have been made to modify mRNAs for increased translation efficacy including modifications in the $5^{\prime}$ cap or $5^{\prime}$ and 3' UTRs and adjustment of the length of the poly-A tail. For instance, anti-reverse cap structure (ARCA) is introduced into mRNAs instead of a normal $5^{\prime}$ cap to produce mRNA with a specifically directed cap [53, 74, 75].

The first attempt to utilize the conventional mRNA vaccines for the protection against influenza in animals was reported by Petsch et al. [46]. Among various infectious diseases, influenza has received a lot of attention because of its impact on global public health [23]. Several vaccines have been developed to fight against seasonally evolving influenza viruses $[23,76]$. Annually, the combination of antigens included in the influenza vaccine is updated in response to the emergence of new strains. Because influenza viruses frequently change their antigenshemagglutinin (HA) and neuraminidase (NA) - a rapid vaccine production system is necessary to prevent an epidemic or pandemic [77]. mRNA vaccines have a great potential for the appropriate design of an antigen combination in the influenza vaccine system owing to their simple and scalable production system [21]. Petsch et al. tested whether the mRNA vaccines encoding full-length HA of influenza A/ PuertoRico/8/1934 (PR8HA) protect against a lethal virus challenge in mice [46]. In addition, they validated the vaccination efficacy of mRNA vaccines lyophilized and stored without a cold chain system. The mRNA vaccines encoding PR8HA were complexed with protamine and administered intradermally (i.d.) to mice twice with a 3-week interval. Figure 2(a) shows that mRNA vaccines, regardless of the storage (a)

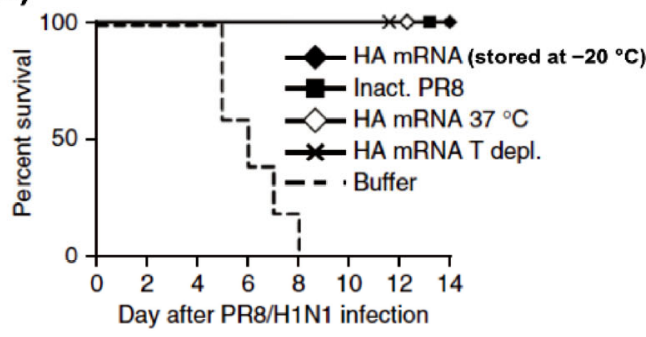

(b)

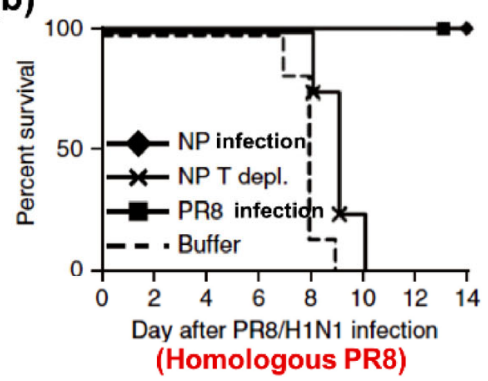

(c)

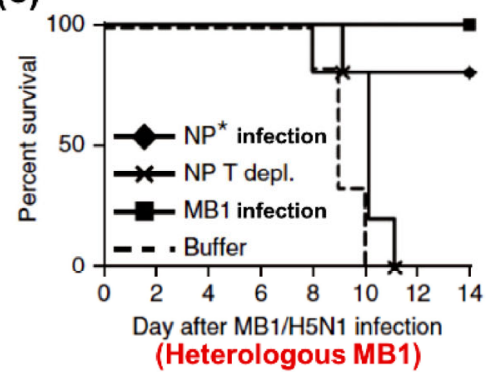

Figure 2 (a) The protective effect of an mRNA vaccine against PR8 virus infection. First, BALB/c mice were injected i.d. with mRNA encoding HA of PR8 virus, after different storage conditions. This result suggests that the vaccines stored at -20 or $37{ }^{\circ} \mathrm{C}$ before injection had similar protective effects. Second, BALB/c mice depleted of CD4 ${ }^{+}$and $\mathrm{CD} 8^{+} \mathrm{T}$ cells were injected with the mRNA vaccine, suggesting that the protective effect of the mRNA vaccine was mediated by antibody induction. (b) and (c) The protective effect of the mRNA vaccine was validated after a challenge with a homologous (PR8) or heterologous (MB1) virus. Before the viral challenge, $\mathrm{BALB} / \mathrm{c}$ mice were injected i.d. with mRNA encoding PR8 NP, suggesting that there was induction of protective effects by the mRNA vaccine against both homologous and heterologous virus infections. Reproduced with permission Ref. [46], C Macmillan Publishers 2012. 
conditions (HA mRNA stored at $-20^{\circ} \mathrm{C}$ and $\mathrm{HA}$ mRNA stored at $37^{\circ} \mathrm{C}$ ), successfully protected mice from infection without tell-tale clinical signs similar to those of the inactivated PR8 virus vaccine (Inact. PR8). Furthermore, the mice that were depleted of $\mathrm{CD}^{+}$and $\mathrm{CD}^{+} \mathrm{T}$ cells were protected successfully, suggesting that the protection from viral infection was mediated by mRNA vaccine-induced antibodies. To verify the protective effect of mRNA vaccines against a heterologous virus, the mRNA vaccines encoding influenza virus nucleoprotein (NP) called PR8 (PR8NP) were designed based on the previous results showing the potential of NP vaccines for cross-protection against a heterologous virus. The mRNA vaccines encoding PR8NP completely protected the mice challenged by homologous PR8 and induced protection in the mice challenged by heterologous MB1 (Figs. 2(b) and 2(c)). The survival rate was markedly decreased in the groups depleted of $\mathrm{CD} 4^{+}$ and $\mathrm{CD}^{+} \mathrm{T}$ cells, verifying that the cross-protective effect was mediated by $\mathrm{T}$ cells.

\subsection{Self-amplifying mRNA vaccines}

To enhance the potency of mRNA vaccines, SAMs also called RNA replicon vaccines have been extensively investigated as a new type of mRNA vaccines [44, 45] Various studies have shown successful results, thus indicating an enhanced vaccination effect of SAM compared with conventional mRNA vaccines [78]. The SAM is based on the replicons derived from various RNA viruses such as alphavirus. The structural differences between conventional nonamplifying mRNA vaccines and SAM are illustrated in Fig. 3. The structure of an alphavirus-based SAM is also presented in Fig. 3. The alphavirus genome contains two genes: one encoding an RNA-dependent RNA polymerase (nonstructural protein), which is capable of copying RNA, and the other gene encoding viral components including capsid and glycoproteins (structural proteins). In the vaccine, a structural gene of RNA replicons is replaced with specific antigens of interest. Thus, the SAM induces abundant antigen expression inside the cells transfected with SAM. Moreover, the intermediates produced during amplification of replicon RNAs are double-stranded RNAs, which stimulate innate immunity.

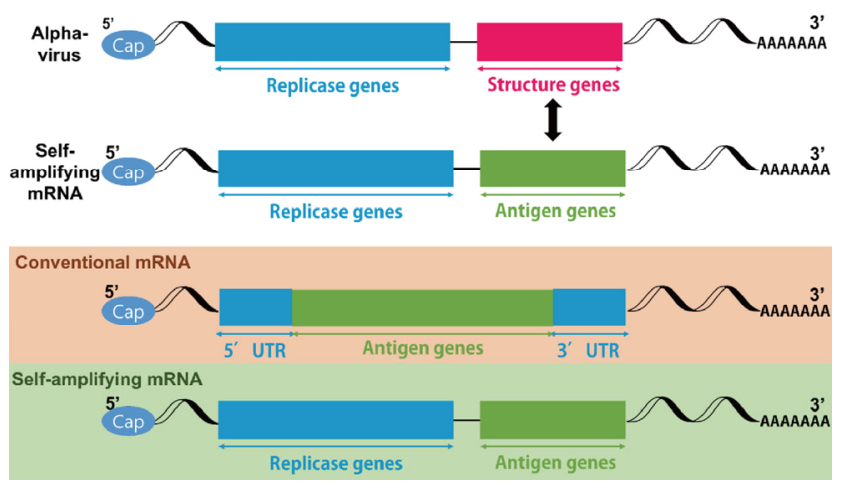

Figure 3 Schematic illustration of self-amplifying mRNA derived from alphavirus and a comparison between conventional mRNA and self-amplifying mRNA.

Among various companies developing mRNA vaccines, Novartis has mostly focused on the creation of mRNA vaccines based on the SAM vaccine technology [78, 79]. They have attempted to deliver the SAM via nonviral delivery vectors. One of the attempts was reported by Geall et al. based on lipid nanoparticles (LNPs) [78]. In previous studies, LNPs had been extensively utilized as delivery materials for small interfering RNA (siRNA), as one of the most powerful strategies of RNA delivery [80, 81]. Geall et al. used various lipid components including the ionizable cationic lipid 1,2-dilnoleyloxy-3dimethylaminopropane (DLinDMA), polyethylene glycol-conjugated (PEGylated) lipids, and cholesterol for the preparation of LNPs (Fig. 4(a)) [78]. The SAM vaccines were encapsulated inside the LNPs via an electrostatic interaction between a cationic lipid and anionic SAM. To verify whether the SAM induces the expression of target proteins in vivo, the SAM encoding secreted alkaline phosphatase (SEAP) as a reporter protein was formulated with LNPs and administered i.m. As presented in Fig. 4(b), the SAM formulated inside the LNPs increased the magnitude of protein expression in mice compared with the mice treated with a 10-fold higher dose of naked RNA. Nonetheless, the mice injected with a simple mixture of the SAM and LNPs without encapsulation showed decreased protein expression as compared with SAM-encapsulating LNPs. This result suggested that encapsulation of SAM is needed for sufficient protein expression. Based on these successful results, the researchers extended the formulation of SAM- 
(a)

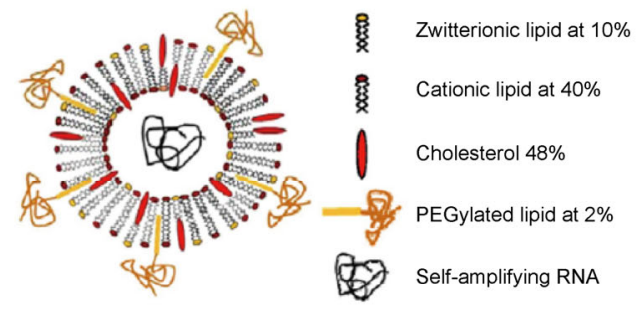

(b)

(c)
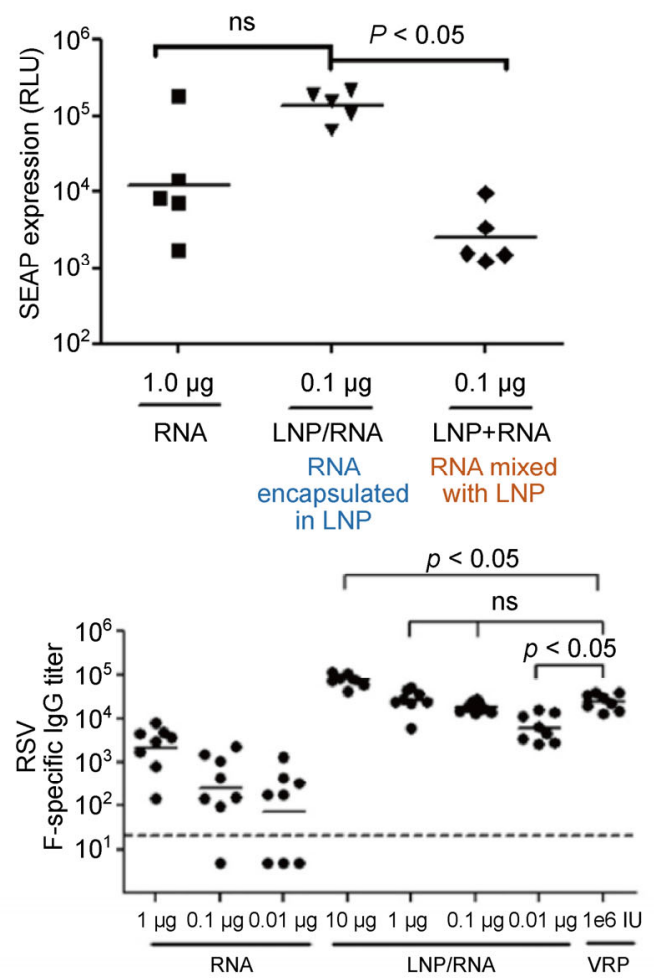

(d)

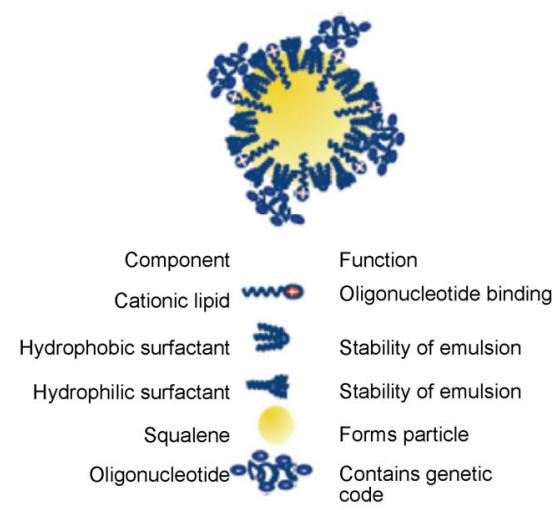

(e)

(f)
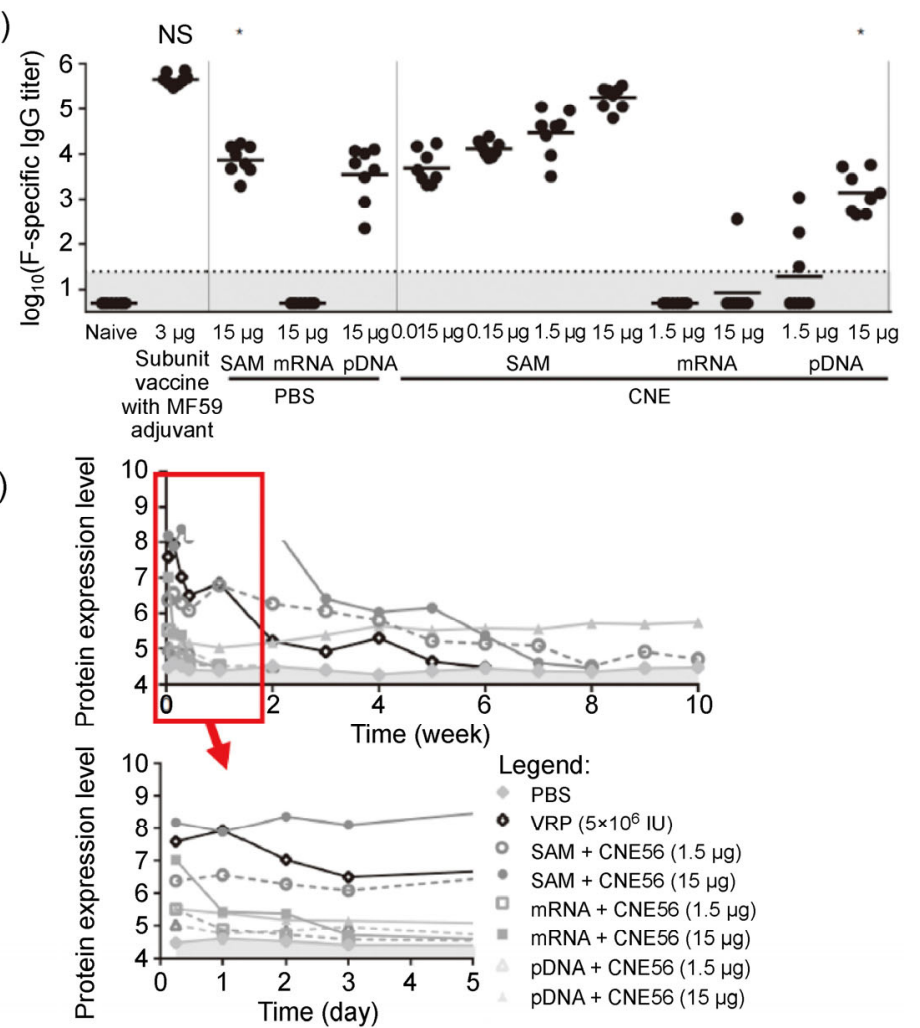

Figure 4 (a) Schematic illustration of SAM encapsulated in LNPs. LNPs were prepared from different types of lipid including a cationic lipid (DLinDMA), PEGylated lipids, and cholesterol. (b) Verification of target protein expression driven by SAM. SAM encoding a reporter protein (SEAP) was encapsulated in LNPs or mixed with LNPs and injected i.m. into mice, indicating successful protein expression by SAM after encapsulation in LNPs. (c) Immunogenicity of SAM encapsulated in LNPs. SAM encoding RSV-F was injected i.m. into mice either in the naked form or encapsulated into LNPs. RSV-F-specific IgG titers were measured by an enzyme-linked immunosorbent assay. SAM encapsulated in LNPs had greater immunogenicity as compared with the naked SAM and was similar to or better than VRP in this regard. (d) Schematic illustration of SAM complexed with CNE. CNE was based on MF59, which has been used in Novartis' influenza vaccine. CNE comprised a cationic lipid interacting with SAM. (e) The dose-dependent protective effect of SAM formulated with CNE and other nucleic acid vaccines. Nucleic acid vaccines encoding RSV-F were injected i.m. into BALB/c mice. F-specific IgG titers were measured by an enzyme-linked immunosorbent assay to verify immunogenicity. SAM formulated with CNE showed a stronger immune response than did naked and CNE-complexed nucleic acid vaccines. Especially, SAM formulated with $15 \mu \mathrm{g}$ of CNE showed an immune response similar to that elicited by a subunit vaccine containing the MF59 adjuvant. (f) Time-dependent protein expression driven by SAM. The mRNA, pDNA, and SAM encoding luciferase were formulated with CNE and injected i.m. into BALB/c mice. SAM formulated with CNE showed the strongest protein expression, which lasted up to 8 weeks, whereas protein expression from mRNA lasted up to 3 days. Reproduced with permission Refs. [78, 82], (C) National Academy of Sciences 2012 and Elsevier B.V. 2014, respectively. 
LNPs to the vaccine system. The SAM encoding the F protein of respiratory syncytial virus (RSV-F) was designed and formulated with LNPs. The immunogenicity of the SAM in the LNP formulation was compared with that of naked SAM and viral replicon particles (VRP), one of the viral vectors. Although the naked SAM showed less immunogenicity than the VRP did, the SAM formulated with LNPs induced an immunogenic effect similar to or even greater than that of the VRP (Fig. 4(c)). This study revealed the great potential of LNPs as a SAM delivery vehicle.

In a more recent study, Novartis used cationic nanoemulsion (CNE) for the delivery of SAM (Fig. 4(d)) [82]. In this study, 1,2-dioleoyl-sn-glycero-3phosphocholine (DOTAP) served as a cationic lipid for the electrostatic interactions with the SAM. Indeed, the CNE was based on MF59, Novartis' proprietary adjuvant used in a commercially developed influenza vaccine. The safety profile and efficacy of MF59 adjuvants have been established in clinical trials [83, 84]. Thus, MF59 showed great promise as a nonviral delivery system. To demonstrate immunogenicity of the SAM complexed with CNE, the SAM encoding the RSV-F protein was utilized. The F-specific IgG titers measured in all groups treated with various doses of the CNEformulated SAM were similar or higher than those in the groups treated with naked mRNAs, naked plasmid DNA (pDNA), CNE-formulated conventional mRNA, or CNE-formulated pDNA (Fig. 4(e)). Especially, the SAM formulated with $15 \mu \mathrm{g}$ of CNE showed superior immunogenicity almost equivalent to that of subunit vaccines containing MF59 as an adjuvant. In addition to the immunogenicity study, the expression profiles of various nucleic acid vaccines including conventional mRNA, SAM, and pDNA were compared using luciferase as a model protein. Although the conventional mRNAs lost their activity within 3 days after administration, the SAM showed longer duration of expression: until 56 days after the injection. The expression of pDNA was quite low compared with both mRNA vaccines (conventional mRNA vaccines and SAM), but with sustained activity, longer than the conventional mRNAs. This finding points to the powerful vaccination effect of SAM compared with conventional mRNA vaccines (Fig. 4(f)).

\section{Cancer immunotherapy}

The ultimate goal of cancer therapeutics is elimination of cancer cells while protecting healthy cells [85, 86]. In the early days of development, various chemical agents targeting rapidly dividing cells such as neoplastic cells were utilized $[85,87,88]$. Nevertheless, chemotherapeutic agents lack selectivity because they also attack normal cells, particularly, rapidly dividing cells such as skin, hair, and intestinal cells $[85,86,88]$. To circumvent this issue, researchers have focused on the creation of targeted therapies that act on specific cancer cells [85, 86, 88-90]. Nonetheless, the clinical outcomes are limited in patients resistant to targeted therapies [91-93]. Recently, a novel treatment strategy was developed by boosting the immune system in patients via cancer immunotherapy to attack cancerous cells [11, 13, 94-96].

Immune checkpoint blockade is one strategy of cancer immunotherapy with a successful therapeutic outcome [94-97]. Immune checkpoints are molecules in the immune system that either stimulate or inhibit an immune response. Among various cancer-related immune checkpoints, CTL-associated antigen 4 (CTLA-4) and programmed cell death protein 1 (PD-1) have been widely studied $[95,96,98,99]$. The DCs presenting specific tumor antigens interact with $\mathrm{T}$ cells by binding to the T-cell receptor (TCR). To activate the $\mathrm{T}$ cells after interaction with DCs, a B7 molecule-mediated stimulatory signal is required. The stimulatory signal is induced by the interaction between B7 molecules and CD28. Conversely, T-cell activation is inhibited by the binding of $B 7$ molecules to CTLA- 4 instead of CD28. In addition, when PD-1 binds to its ligands, the antigen-specific $\mathrm{CD} 8{ }^{+} \mathrm{T}$ cells lose their cytotoxic effect. Thus, anti-CTLA-4 or anti-PD-1 monoclonal antibodies can be utilized to stimulate the immune system by blocking the immunoinhibitory reaction $[100,101]$. Indeed, the anti-CTLA-4 antibodies and anti-PD-1 antibodies exert a sufficient therapeutic effect against various tumors [100, 102-106].

Therapeutic cancer vaccines are another strategy of cancer immunotherapy [13, 14, 107, 108]. Normally, cancer cells maintain their aggressiveness by hiding from the immune system $[109,110]$. Various genetic and epigenetic mutations in cancer cells enable their 
escape and uncontrollable growth [109, 110]. Therapeutic vaccines developed for cancer immunotherapy are designed to educate immune cells to detect cancer cells as abnormal cells and eventually attack the tumors [63, 111-114]. APCs play an important role in the mechanism of action of therapeutic cancer vaccines $[115,116]$. In particular, DCs are the most potent APCs that bridge innate and adaptive immune responses primarily by sensitizing naïve $\mathrm{T}$ cells to specific antigens [117-119]. Several properties suggest that DCs are the most potent APCs. First, DCs are commonly found at the sites of entry such as skin, the stomach, and lungs. Second, DCs capture antigens and once activated, DCs migrate to lymph nodes containing naïve $\mathrm{T}$ cells. Third, mature DCs strongly express MHC and costimulatory molecules such as cytokines and chemokines. Finally, DCs have the ability to induce an immune response via crosspresentation of extracellular antigens on MHC class I molecules, thereby activating $\mathrm{CD} 8^{+} \mathrm{T}$ cells.

Via delivery of mRNA therapeutic vaccines encoding specific tumor antigens into DCs, the encoded proteins can be presented onto the surface of DCs, activating CTLs via the aforementioned immune reaction $[63,113,114,120]$. A mechanism of mRNA vaccine-mediated, DC-based immune response is illustrated in Fig. 1. Target antigens are expressed in DCs by in vivo or ex vivo delivery of mRNA vaccines encoding the antigens. Upon recognition of the immune stimuli, immature DCs differentiate into mature DCs, followed by increased expression of MHC class I molecules and various cytokines and chemokines [53, 117-119, 121]. The antigens presented on MHC class I molecules induce the activation of effector CTLs. Although exogenous antigens are presented by MHC class II molecules, the exogenous antigens can also be presented by MHC class I molecules via specific cellular pathways called crosspresentation in DCs $[122,123]$. Thus, both endogenous and exogenous antigens can be presented on the surface of mature DCs via an MHC class I molecule and ultimately prime antigen-activated CTLs. Because the antigen-specific CTLs are the key immune cells attacking cancerous cells, cancer immunotherapy is mostly based on DC-mediated immunity.

Two major approaches have been developed for the delivery of mRNA vaccines into DCs. First, mRNA vaccines are transfected into the DCs harvested from patients ex vivo [113, 114, 124]. The DCs harvested and subsequently transfected with an mRNA vaccine are transferred back into patients for the immunotherapeutic effect. Various gene transfection strategies have been devised to deliver mRNA vaccines into DCs in vitro. These include physical gene transfection methods such as electroporation and microinjection and chemical gene transfection agents such as positively charged lipids or polymers that form lipoplexes or polyplexes via electrostatic interaction with a negatively charged mRNA vaccine. Given that the activation and antigen presentation in DCs can be precisely controlled in vitro, it is possible to control the efficiency of a DC-mediated immune reaction. On the other hand, this method has been considered tedious and expensive.

Recently, many researchers developed various delivery strategies that deliver mRNA vaccines directly in vivo [114, 124, 125]. According to several studies on the development of anticancer therapeutic vaccines, systemically delivered mRNA vaccines result in a more potent immunization effect than do locally delivered mRNA vaccines injected i.m. or i.d. Although the naked mRNA vaccines injected i.m. or i.d. can induce some immunization effect with weak antigen expression in APCs, they can quickly degrade and lose their effect before reaching APCs especially when they are injected intravenously (i.v.). Thus, delivery materials are prerequisite for the systemic administration of mRNA vaccines. Various nonviral delivery carriers including lipid or polymeric nanoparticles have been developed for this purpose. The delivery carriers can be designed to control antigen presentation in DCs and maturation of DCs [67, 71, 126]. The hydrodynamic sizes, surface charges, and hydrophobicity of delivery materials affect the distribution and cellular uptake efficiency of mRNA. Although the particles with small size (100-200 nm) can reach lymphoid organs by entering lymphatic vessels, larger particles need to be carried by DCs or macrophages to reach lymphoid organs [127, 128]. Because the specific DCs that can cross-present antigens to induce CTLs are mainly located in lymph nodes, the small-molecule delivery materials would 
be more adequate for mRNA vaccines for cancer immunotherapy. Furthermore, via conjugation of various adjuvant molecules (e.g., CpG, Alum) with delivery materials, the mRNA vaccine effect can be further enhanced.

Delivering mRNA vaccines into patients' DCs in vivo is a greater challenge compared with ex vivo delivery of mRNA vaccines into harvested DCs. Nonetheless, in vivo delivery of mRNA vaccines is the ultimate goal of DC-mediated cancer immunotherapy There exists a variety of gene delivery systems designed for the delivery of nucleic acid drugs such as plasmid DNA and siRNA. By means of the accumulated knowledge on those gene delivery systems, it is expected that the development of a robust mRNA vaccine delivery system can be achieved. In this section, several studies on the development of mRNA vaccines for DC-mediated cancer immunotherapy are discussed.

\subsection{Preparation of DC-based vaccines by ex vivo delivery of mRNA}

Delivering mRNA vaccines encoding tumor antigens into DCs ex vivo was one of the earliest approaches utilized in cancer immunotherapy [113, 114, 124, 125]. In addition to DCs, other immune cells such as $\mathrm{T}$ cells have been engineered and applied to cancer immunotherapy. Among the immune-cell-based immunotherapeutic agents, the mRNA vaccine technology shows great promise due to its powerful ability to express the desired protein in the transfected cells. In DCs, tumor-specific antigens or other immunostimulatory molecules are expressed by transfection of mRNA vaccines to obtain antigen-specific mature DCs. Subsequently, the mRNA-transfected DCs are administered back into the cancer patients. The DC-based vaccines prepared from patients' own DCs are called autologous vaccines. Because the autologous cells from the patients are utilized throughout the whole process, autologous vaccines are considered safe: free of the risk of unwanted immunogenicity. Several DC-based vaccines engineered to express tumor antigens ex vivo have been effective against tumor cells in various preclinical and clinical studies. The US Food and Drug Administration (FDA) approved
Sipuleucel-T in 2010, the first autologous cell-based cancer immunotherapy for the treatment of metastatic hormone-resistant prostate cancer. In November 2016, 712 DC-based immunotherapies have been advanced to human clinical trials (2016, http://www. clinicaltrials. gov). Among the various clinical trials, only Sipuleucel$\mathrm{T}$ was successful for commercial manufacture.

One example of DC-based vaccines prepared by transfecting autologous tumor mRNAs into DCs was reported by Kyte et al. [129]. They reported a phase I/II trial of a newly developed autologous tumor mRNA-loaded DC-based vaccine. The tumor mRNAs extracted from patients' tumor biopsies were delivered into DCs via electroporation. The tumor mRNAelectroporated DCs were administered to melanoma patients via intranodal or i.d. injections. Approximately $50 \%$ of DC-treated patients were confirmed to have antigen-specific T-cell responses, which might improve the survival rates. Of note, the patients treated with i.d. injection showed better DC vaccine-induced immune responses as compared to the patients treated with intranodal injection. A possible further maturation process that occurred during the migration of DCs from an i.d. injection site toward a lymph node was suggested as a reason for the better immune response than that with the intranodal injection. The immune responders manifesting an antigen-specific immune reaction showed improved survival, indicating a great potential of DC-based vaccines in melanoma cancer patients. They also suggested that the combination therapy of DC-based vaccines and immune checkpoint blockade would be more powerful cancer therapeutics than the monotherapy of DC-based vaccines or immune checkpoint blockade.

Another example of DC-based vaccine development by the mRNA technology was reported by Bonehill et al. [113]. As described above, in order to prime CTLs to attack specific cancer cells, DCs should not only present sufficient amounts of antigens but also induce immunostimulatory signals for their activation and maturation. Several studies have shown that the maturation and activation of DCs can be improved via expression of specific immunomodulatory molecules. Bonehill et al. utilized the mRNA encoding several immunomodulatory molecules to enhance the efficacy 
of DC-based vaccines. They delivered a combination of three mRNAs, each encoding CD40 ligand (CD40L), CD70, and constitutively active Toll-like receptor 4 (caTLR4). It has been reported that the DCs expressing CD40L increase the therapeutic effect in tumors via overexpression of immunostimulatory molecules, cytokines, and chemokines. CD70, the ligand of CD27, performs an important function in the priming of $\mathrm{CD}^{+} \mathrm{T}$ cells. In addition, lipopolysaccharide (LPS), which binds to TLR4, is known to mediate the most potent DC-activating signals. Nevertheless, using LPS clinically is considered dangerous because LPS invokes an acute inflammatory response. In that study, it was suggested that the caTLR4-expressing DCs acted similarly to DCs stimulated by LPS. Based on these mechanisms, it was expected that the DCs expressing CD40L, CD70, and caTLR4 would show great potency in DC-based vaccination.

Three mRNAs encoding CD40L, CD70, and caTLR4 were delivered into DCs via electroporation. The levels of secretion of cytokines and chemokines in the DCs simultaneously expressing CD40L, CD70, and caTLR4 were compared with those of immature DCs and the DCs exposed to a cytokine cocktail containing IL-1 $\beta$, IL-6, TNF- $\alpha$, and PGE2. The immature DCs and the cytokine-treated DCs were electroporated with irrelevant mRNAs (NGFR). The DCs expressing all three immunomodulatory molecules (CD40L+CD70+ caTLR4) showed the highest levels of secretion of all cytokines and chemokines listed in Fig. 5(a) as compared with the immature DCs and the cytokinetreated DCs. In addition, the investigators stimulated naïve $\mathrm{CD}^{+} \mathrm{T}$ cells with $\mathrm{DCs}$ electroporated with different combinations of mRNAs and subsequently pulsed with the MelanA-A2 peptide to determine whether the prepared DCs prime antigen-specific $\mathrm{CD}^{+} \mathrm{T}$ cells (Fig. 5(b)). The induction magnitude of MelanA-specific $\mathrm{CD}^{+} \mathrm{T}$ cells was far greater in the $\mathrm{T}$ cells stimulated with DCs expressing three mRNAs (CD40L+CD70+caTLR4) than in DCs expressing single mRNA or two mRNAs (CD40L+CD70 or CD40L+caTLR4). In summary, this study showed that various molecules associated with activation and maturation of DCs are successfully expressed in DCs using mRNAs encoding the molecules, and thereby enhance the priming of antigen-specific $\mathrm{CD} 8^{+} \mathrm{T}$ cells.

\subsection{In vivo delivery of mRNA vaccines to DCs}

Several attempts at in vivo delivery of mRNA therapeutics have been made to protect mRNA from (a)

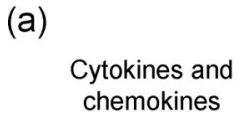

\begin{tabular}{lcccc}
\multicolumn{2}{c}{ chemokines } & $\begin{array}{c}\text { expressing } \\
\text { NGFR }\end{array}$ & $\begin{array}{c}\text { CD40L+CD70+ } \\
\text { caTLR4 }\end{array}$ & $\begin{array}{c}\text { expressing } \\
\text { NGFR }\end{array}$ \\
\hline Cytokines & IL-1 $\beta$ & 7.2 & 146 & 3.5 \\
& IL-6 & 754 & $>20,000$ & 1,093 \\
& IL-10 & 43.4 & 902 & 54.1 \\
& G-CSF & 140 & 8,553 & 68 \\
& GM-CSF & 9 & 101 & 10.3 \\
& IFN- $\gamma$ & 51.5 & 508 & 71.6 \\
& TNF- $\alpha$ & 87.2 & $>20,000$ & 20 \\
Chemokines & IL-8 & 10,521 & $>30,000$ & 3,143 \\
& MIP-1 $\alpha$ & 175 & 917 & 120 \\
& IP-10 & 1,076 & $>20,000$ & 50.5 \\
& RANTES & 1,071 & $>20,000$ & 598 \\
\hline
\end{tabular}

(b)

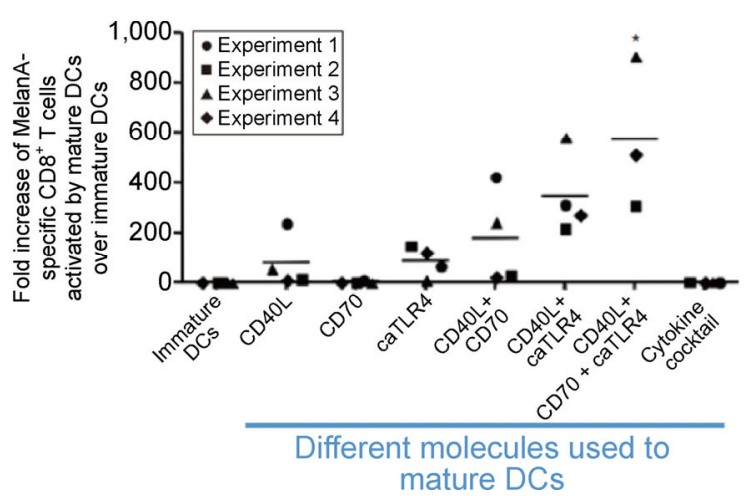

Figure 5 (a) Cytokine and chemokine production by DCs electroporated with various mRNAs. Immature DCs were electroporated with irrelevant NGFR mRNA or CD40L +CD70+caTLR4, and cytokine cocktail-matured DCs were electroporated with irrelevant NGFR mRNA. CD40L+CD70+caTLR4-electroporated DCs secreted greater amounts of cytokines and chemokines than did immature DCs and cytokine cocktail-matured DCs expressing irrelevant NGFR. (b) The fold increase in the number of MelanA-specific CD8 ${ }^{+} \mathrm{T}$ cells compared with MelanA-nonspecific $\mathrm{CD}^{+} \mathrm{T}$ cells stimulated by DCs. Naïve $\mathrm{CD} 8^{+} \mathrm{T}$ cells were stimulated by either MelanA-A2 peptide-electroporated DCs or irrelevant NGFR mRNA-electroporated DCs. Besides, DCs were coelectroporated with CD40L/CD70/ caTLR4 mRNAs and treated with a cytokine cocktail. DCs expressing all three costimulatory molecules (CD40L+CD70+caTLR4) showed higher induction levels of MelanA-specific $\mathrm{CD}^{+} \mathrm{T}$ cells. Reproduced with permission Ref. [113], C Elsevier B.V. 2008. 
the harsh conditions of serum and to safely deliver these molecules to target cells. Via such mRNA delivery methods, the mRNA vaccines can also be delivered into the target DCs, resulting in DC-mediated immunity for cancer immunotherapy eventually. On the other hand, the delivery vehicles for mRNA vaccines need to exert immunostimulation in addition to powerful mRNA delivery efficiency to yield sufficient levels of vaccination. Given that mRNAs have immunostimulatory effects via recognition by a variety of immune sensors such as endosomal TLRs and cytoplasmic RNA sensors (RIG-1, MDA5), mRNA vaccines trigger partial immune stimulation without additional adjuvants, suggesting that mRNA vaccines are more attractive than DNA vaccines. The delivery vehicles for mRNA vaccines can further boost the immunostimulatory effects to achieve an enhanced antitumor immune response.

Self-adjuvanted vaccine (RNActive ${ }^{\circledR}$ ), developed by CureVac, illustrates the requirements of an mRNA vaccine system, including in vivo delivery of mRNAs and immune stimulation [63]. The RNActive ${ }^{\circledR}$ vaccine $^{2}$ consists of mRNA encoding antigens and protamine. The latter serves for complexation with the mRNA and immunostimulatory effects. The mRNA sequence of the RNActive ${ }^{\circledR}$ vaccine was carefully optimized by increasing guanine-cytosine (GC) content in the ORF region, introducing $\beta$-globin UTRs, and modulating the length of the poly-A tail. Via optimization, the expression levels of antigens can be maximized by increasing the translation efficiency of mRNA. Protamine, a peptide with a positive charge, was complexed with mRNA, forming mRNA-protamine particles. These particles, prepared at a weight ratio of 2:1 (mRNA:protamine), induced abundant IL-12 secretion (Fig. 6(a)). In contrast, the TLR7 knockout mice treated with the mRNA-protamine complex did show any sign of the immunostimulatory effect, suggesting that the immunostimulatory effect of mRNA-protamine complexes was mediated by TLR7 (Fig. 6(b)). To maximize the capability of RNActive ${ }^{\circledR}$ in both antigen expression levels and immune stimulation, a mixture of free mRNA and an mRNA-protamine complex was prepared. The mixture encoding the GgOVA antigen showed considerable anticancer therapeutic effects in mice carrying E.G7-OVA tumors, whereas only a negligible therapeutic effect was observed in mice treated with a control vaccine encoding unrelated (a)

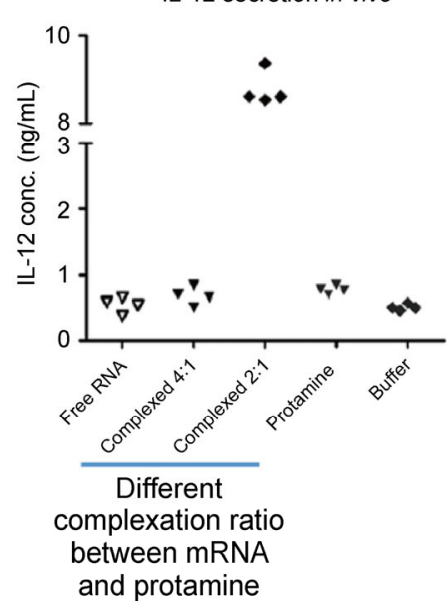

(b)

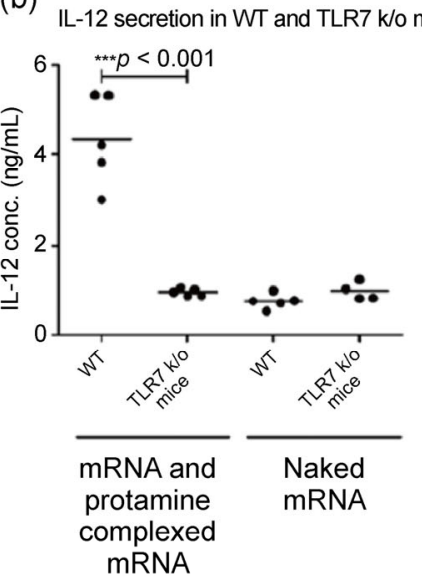

(c) Time course of E.G7-OVA tumor growth Time course of E.G7-OVA tumor growth
upon different start of therapeutic vaccination

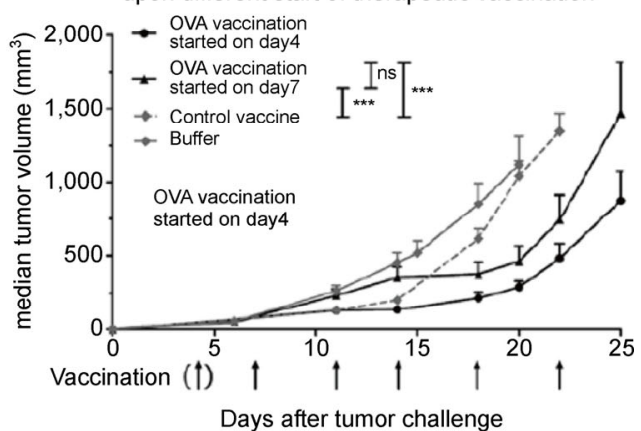

Figure 6 (a) Immunogenicity of the mRNA-protamine complex in different ratios. Serum levels of IL-12 were validated after i.v. injection of naked mRNA, protamine, or the mRNA-protamine complex into BALB/c mice. A 2:1 ratio in the mRNA-protamine complex caused a stronger immunostimulatory effect than did naked protamine or the mRNA-protamine complex at 4:1. (b) Validation of immune stimulation by the mRNA-protamine complexes mediated by TLR7. The mRNA encoding PpLUC was i.d. injected either in the naked form or as an mRNA-protamine complex into WT mice or TLR7 knockout mice; the results suggested that the immune stimulation effect was mediated by TLR7. (c) The antitumor response elicited by the mRNA-protamine complex encoding GgOVA. C57BL/6 mice were challenged s.c. with the E.G7-OVA tumor on day 0 and vaccination started on different days. OVA vaccination yielded a considerable anticancer effect compared with a control vaccine encoding irrelevant mRNAs. Reproduced with permission Ref. [63], (C) Wolters Kluwer Health, Inc. 2011.

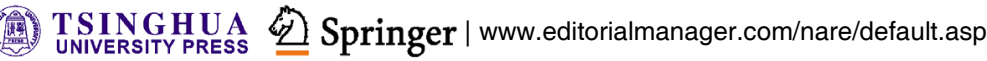


antigens (Fig. 6(c)). Until now, CureVac has applied the newly developed RNActive ${ }^{\circledR}$ technology to the treatment of various cancers, including non-small cell lung cancer and prostate cancer, and reported numerous results demonstrating the great potential of the RNActive ${ }^{\circledR}$ technology in cancer immunotherapy [130, 131].

BioNtech, another mRNA company, developed a lipid-based formulation for mRNA vaccine delivery in cancer immunotherapy [114]. Although RNActive ${ }^{\circledR}$ is injected i.d., the lipid-formulated mRNA vaccine was developed as a systemically available mRNA vaccine. To ensure adequate potency of a DC-mediated immune response after systemic administration, mRNA vaccines should be delivered specifically into DCs. A variety of researchers have attempted to deliver antigens into target DCs by introducing targeting molecules that bind to the surface of DCs [132]. Compared with other attempts utilizing targeting molecules, the targetability of mRNA vaccines to DCs was modulated by adjusting the surface charges of lipid formulations in mRNA vaccines. Various lipid formulations with different surface charges have been prepared from lipids such as $\mathrm{N}-[1-(2,3-$ dioleyloxy)propyl]-N,N,N-trimethylammonium chloride (DOTMA), DOTAP, and 1,2-dioleoyl-sn-glycero-3phosphoethanolamine (DOPE). To demonstrate the tissue targeting by a prepared lipid formulation, a lipid formulation of mRNA encoding luciferase as a model protein was prepared and systemically injected. As shown in Fig. 7(a), the positively charged lipid formulation induced strong luminescence in

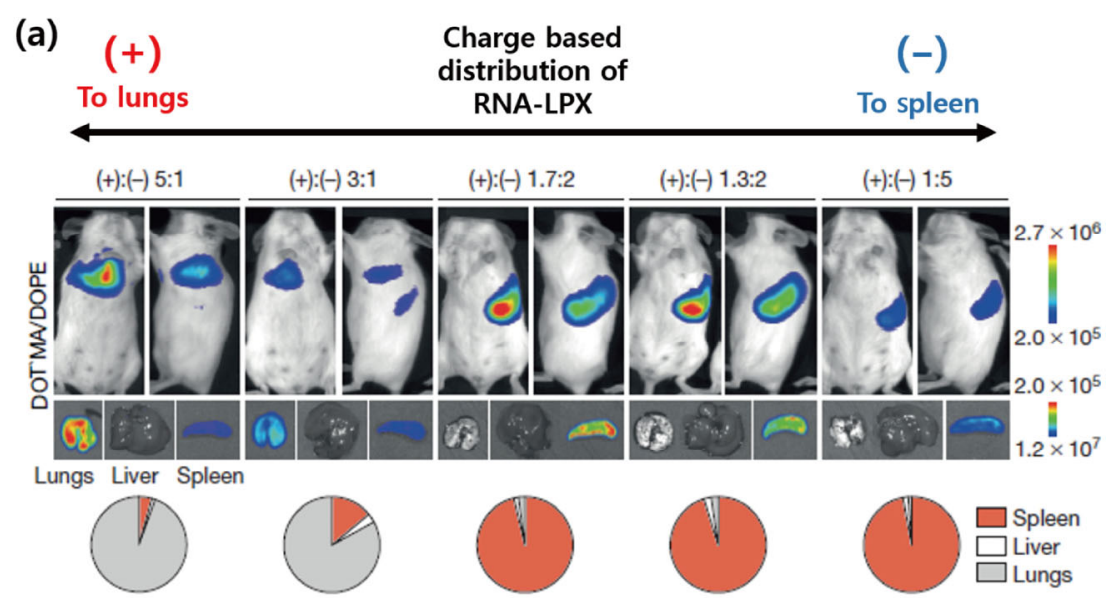

(b)

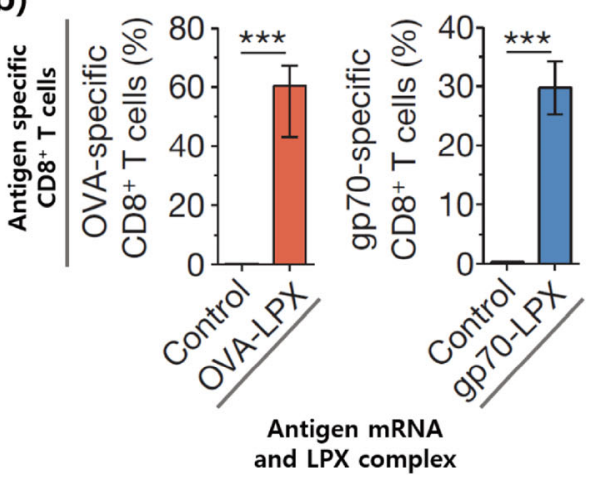

(c)

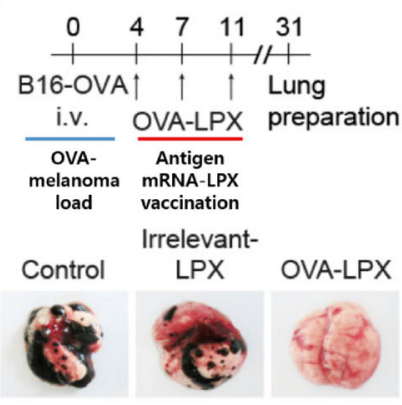

Figure 7 (a) Charge-based distribution of a lipid formulation of luc mRNA. BALB/c mice were injected i.v. with luc mRNA formulated with lipids of different charges. Positively charged particles were mostly distributed in lungs, and negatively charged particles were mostly distributed in the spleen. (b) Expansion of antigen-specific $\mathrm{CD} 8^{+} \mathrm{T}$ cells under the influence of the lipid formulation of mRNA encoding different antigens. C57BL/6 mice and BALB/c mice were immunized i.v. with either mRNA encoding OVA or gp70; the results indicated successful expansion of antigen-specific CD $8^{+} \mathrm{T}$ cells by mRNA. (c) The antitumor response caused by the lipid formulation of mRNA. The mRNA encoding an irrelevant antigen or OVA antigen lipid formulations were injected i.v. into OVA-melanoma. Reproduced with permission Ref. [114], (C) Macmillan Publishers Limited 2016. 
lung tissues, whereas the neutral or negatively charged formulation induced signals in the spleen. Based on this result, the slightly negatively charged lipid formulation was selected as the most potent formulation for vaccination. The lipid formulation of mRNA encoding ovalbumin (OVA) or gp70 (an antigen of murine leukemia virus) successfully induced formation of antigen-specific $\mathrm{CD} 8^{+} \mathrm{T}$ cells (Fig. 7(b)). In addition, the lipid formulation of mRNA encoding OVA exerted a significant therapeutic effect in a mouse model of B160-OVA melanoma (Fig. 7(c)). In this study, it was emphasized that a significant cancer immunotherapeutic effect can be achieved by means of systemic lipid formulations as compared with subcutaneous (s.c.) delivery of mRNA vaccines. Indeed, when the lipid formulation of mRNA encoding OVA was injected systemically, a larger number of OVA-specific CD8 ${ }^{+} \mathrm{T}$ cells was induced as compared with s.c. injection. In addition, the s.c. injected lipid formulation of mRNA encoding luciferase induced luminescence only at the injection site.

\section{Future perspectives and a conclusion}

Globalization has caused epidemics or pandemics spreading rapidly worldwide, triggering global public health challenges. To efficiently manage the emergence of new infectious strains and prevent their spread, rapid development of vaccines is imperative [48, 76, 77]. In this regard, nucleic acid vaccines have excited much interest because of their simplicity and a rapid production system. Based on several advantages of mRNAs over plasmid DNA such as high translation efficiency and a strong ability to stimulate an immune response, recent studies have largely focused on the development of mRNA vaccines [21, 38]. The development of techniques to improve the stability of mRNAs has accelerated the widespread application of mRNA vaccines as an alternative to DNA vaccines. mRNA vaccines have traditional prophylactic applications to prevent future infection in addition to a therapeutic role, e.g., cancer immunotherapy. Immunological advances have expanded the scope of mRNA vaccines.

To stimulate a sufficient immune response for immunization, it is essential to present viral antigens on a large scale via APCs. The nonamplifying mRNA vaccines comprising the $5^{\prime}$ cap-based eukaryotic mRNAs are generally utilized in the development of mRNA vaccines. Via optimization of the sequences of $5^{\prime}$ and $3^{\prime}$ UTRs, the $5^{\prime}$ cap structure, and of the length of the poly-A tail, the antigen presentation and the duration of mRNA vaccines can be changed [72, 73]. In addition, self-amplifying mRNAs derived from alphavirus have been devised and show excellent vaccination efficiency, especially in the prevention of future viral infections [44, 45, 78, 79]. Furthermore, efforts to develop delivery techniques for mRNA vaccines have been reported to enhance vaccination efficiency. For instance, the DC-based immune strategy attacking target cancer cells requires appropriate delivery vehicles for the targeted delivery of mRNA vaccines [114, 124, 133, 134]. A few technologies have delivered mRNAs into extracted DCs in vitro, and others have directly delivered mRNAs in vivo [114, $124,134]$. Because the in vitro techniques delivering mRNAs into the extracted DCs are quite tedious, in vivo delivery techniques are thought to represent an ideal strategy.

With the great improvement in various techniques involving nucleic acids and their delivery materials, various proof-of-concept studies have been published $[55,66,78]$. Because the mechanism of vaccination is complex, it may be necessary to modulate multiple target proteins. mRNA vaccines are an ideal candidate for inducing expression of target proteins including antigens or specific molecules required for the stimulation and maturation of immune cells. In addition, via introduction of other functional molecules into mRNA vaccines, novel types of vaccines can be created for therapeutic and prophylactic applications. For instance, targeting ligands that bind to specific immune cells have been incorporated into the delivery vehicles of mRNA vaccines to specifically target a cell type [132]. To further enhance the immunostimulatory effects, various functional RNA therapeutics such as siRNA have been administered to immune cells $[135,136]$. In the field of cancer immunotherapy, such novel types of vaccines show great promise for complete elimination of various cancers. Several biological drugs are clinically 
available for cancer treatment including monoclonal antibodies developed as immune checkpoint inhibitors $[137,138]$. Coadministration of such immunotherapeutic agents along with mRNA vaccines represents a powerful immunotherapeutic strategy to treat cancer.

In the development of prophylactic and therapeutic mRNA vaccines, three major factors require careful modulation. First, the levels of expression and duration of mRNA vaccines should be precisely adjusted in the target immune cells by optimizing the structures of mRNAs. In addition, similar to the RNA replicons derived from viruses with enhanced expression and self-replication in a cellular environment, other viral RNAs can be utilized as a platform for preparation of novel types of mRNA vaccines. Second, appropriate delivery strategies for mRNA vaccines are needed to achieve a sufficient effect. To this end, various gene delivery materials have been developed and are investigated [55, 65, 78]. In the field of development of delivery materials for mRNA vaccines, not only the delivery efficiency of mRNAs but also the immune stimulation effect should be considered for adequate immune responses. Finally, the stimulatory and inhibitory immune signals of immune reactions should be controlled appropriately. To maximize the immune stimulation, mRNA vaccines can be designed to express immunostimulatory proteins along with target antigens. In addition, other RNA therapeutics such as siRNAs can be utilized to suppress the immunoinhibitory signals. Overall, many investigators have reported successful results demonstrating the great potential of mRNA vaccines, some of which are in clinical trials [20, 137, 138]. Nevertheless, a few limitations should be addressed before these vaccines can be used in practical applications. We believe this review provides sufficient information regarding the current status and the future of mRNA vaccines. We hope that this review will lead to breakthroughs in mRNA vaccines by guiding appropriate interdisciplinary studies among various fields of technology such as immunology, pharmaceutics, and biomaterials.

\section{Acknowledgements}

This work is supported by National Research Foundation of Korea (NRF) funded by Ministry of Science,
ICT \& Future Planning (Pioneer Research Center Program (No. 2014M3C1A3054153), Basic Science Research Program (No. 2015R1A1A1A05027352)) and Ministry of Education (Basic Science Research Program (No. 2017R1D1A1B03028278)).

\section{References}

[1] Osterholm, M. T.; Kelley, N. S.; Sommer, A.; Belongia, E. A. Efficacy and effectiveness of influenza vaccines: A systematic review and meta-analysis. Lancet Infect. Dis. 2012, 12, 36-44.

[2] Ruiz-Palacios, G. M.; Pérez-Schael, I.; Velázquez, F. R.; Abate, H.; Breuer, T.; Clemens, S. C.; Cheuvart, B.; Espinoza, F.; Gillard, P.; Innis, B. L. et al. Safety and efficacy of an attenuated vaccine against severe rotavirus gastroenteritis. N. Engl. J. Med. 2006, 354, 11-22.

[3] Bernstein, D. I.; Sack, D. A.; Reisinger, K.; Rothstein, E.; Ward, R. L. Second-year follow-up evaluation of live, attenuated human rotavirus vaccine $89-12$ in healthy infants. J. Infect. Dis. 2002, 186, 1487-1489.

[4] Francis, T.; Salk, J. E.; Quilligan, J. J. Experience with vaccination against influenza in the spring of 1947: A preliminary report. Am. J. Public Health Nations Health 1947, 37, 1013-1016.

[5] Vos, Q.; Lees, A.; Wu, Z. Q.; Snapper, C. M.; Mond, J. J. B-cell activation by T-cell-independent type 2 antigens as an integral part of the humoral immune response to pathogenic microorganisms. Immunol. Rev. 2000, 176, 154-170.

[6] Liu, M. A. Immunologic basis of vaccine vectors. Immunity 2010, 33, 504-515.

[7] Bousquet, J.; Lockey, R.; Malling, H. J. Allergen immunotherapy: Therapeutic vaccines for allergic diseases. A WHO position paper. J. Allergy Clin. Immunol. 1998, 102, 558-562.

[8] Autran, B.; Carcelain, G.; Combadiere, B.; Debre, P. Therapeutic vaccines for chronic infections. Science 2004, 305, 205-208.

[9] Michel, M. L.; Deng, Q.; Mancini-Bourgine, M. Therapeutic vaccines and immune-based therapies for the treatment of chronic hepatitis B: Perspectives and challenges. J. Hepatol. 2011, 54, 1286-1296.

[10] Gröschel, M. I.; Prabowo, S. A.; Cardona, P. J.; Stanford, J. L.; van der Werf, T. S. Therapeutic vaccines for tuberculosisA systematic review. Vaccine 2014, 32, 3162-3168.

[11] Farkona, S.; Diamandis, E. P.; Blasutig, I. M. Cancer immunotherapy: The beginning of the end of cancer? BMC Med. 2016, 14, 73 .

[12] van der Burg, S. H. Therapeutic vaccines in cancer: Moving 
from immunomonitoring to immunoguiding. Expert Rev. Vaccines 2008, 7, 1-5.

[13] Rosenberg, S. A.; Yang, J. C.; Restifo, N. P. Cancer immunotherapy: Moving beyond current vaccines. Nat. Med. 2004, 10, 909-915.

[14] Mellman, I.; Coukos, G.; Dranoff, G. Cancer immunotherapy comes of age. Nature 2011, 480, 480-489.

[15] Finn, O. J. Cancer vaccines: Between the idea and the reality. Nat. Rev. Immunol. 2003, 3, 630-641.

[16] Formenti, S. C.; Demaria, S. Combining radiotherapy and cancer immunotherapy: A paradigm shift. J. Natl. Cancer Inst. 2013, 105, 256-265.

[17] Moreno, C.; Cuesta-Herranz, J.; Fernandez-Tavora, L.; Alvarez-Cuesta, E. Immunotherapy safety: A prospective multi-centric monitoring study of biologically standardized therapeutic vaccines for allergic diseases. Clin. Exp. Allergy 2004, 34, 527-531.

[18] Eggermonf, A. M. M. Therapeutic vaccines in solid tumours: Can they be harmful? Eur. J. Cancer 2009, 45, 2087-2090.

[19] Morera, Y.; Bequet-Romero, M.; Ayala, M.; Velazco, J. C.; Perez, P. P.; Alba, J. S.; Ancizar, J.; Rodríguez, M.; Cosme, K.; Gavilondo, J. V. Immunogenicity and some safety features of a VEGF-based cancer therapeutic vaccine in rats, rabbits and non-human primates. Vaccine 2010, 28, 3453-3461.

[20] Melero, I.; Gaudemack, G.; Gerritsen, W.; Huber, C.; Parmiani, G.; Scholl, S.; Thatcher, N.; Wagstaff, J.; Zielinski, C.; Faulkner, I. et al. Therapeutic vaccines for cancer: An overview of clinical trials. Nat. Rev. Clin. Oncol. 2014, 11, 509-524.

[21] Geall, A. J.; Mandl, C. W.; Ulmer, J. B. RNA: The new revolution in nucleic acid vaccines. Semin. Immunol. 2013, 25, 152-159.

[22] Liu, M. A. DNA vaccines: A review. J. Intern. Med. 2003, 253, 402-410.

[23] Carrat, F.; Flahault, A. Influenza vaccine: The challenge of antigenic drift. Vaccine 2007, 25, 6852-6862.

[24] Soema, P. C.; Kompier, R.; Amorij, J. P.; Kersten, G. F. A. Current and next generation influenza vaccines: Formulation and production strategies. Eur. J. Pharm. Biopharm. 2015, 94, 251-263.

[25] Boni, M. F. Vaccination and antigenic drift in influenza. Vaccine 2008, 26, C8-C14.

[26] Li, W. D.; Joshi, M. D.; Singhania, S.; Ramsey, K. H.; Murthy, A. K. Peptide vaccine: Progress and challenges. Vaccines 2014, 2, 515-536.

[27] Hasan, U. A.; Abai, A. M.; Harper, D. R.; Wren, B. W.; Morrow, W. J. W. Nucleic acid immunization: Concepts and techniques associated with third generation vaccines. $J$. Immunol. Methods 1999, 229, 1-22.

[28] Wolff, J. A.; Malone, R. W.; Williams, P.; Chong, W.;
Acsadi, G.; Jani, A.; Felgner, P. L. Direct gene transfer into mouse muscle in vivo. Science 1990, 247, 1465-1468.

[29] Kutzler, M. A.; Weiner, D. B. DNA vaccines: Ready for prime time? Nat. Rev. Genet. 2008, 9, 776-788.

[30] Sardesai, N. Y.; Weiner, D. B. Electroporation delivery of DNA vaccines: Prospects for success. Curr. Opin. Immunol. 2011, 23, 421-429.

[31] Donnelly, J. J.; Ulmer, J. B.; Liu, M. A. DNA vaccines. Dev. Biol. Stand. 1998, 95, 43-53.

[32] Mahvi, D. M.; Sheehy, M. J.; Yang, N. S. DNA cancer vaccines: A gene gun approach. Immunol. Cell Biol. 1997, 75, 456-460.

[33] Leitner, W. W.; Ying, H.; Restifo, N. P. DNA and RNAbased vaccines: Principles, progress and prospects. Vaccine 1999, 18, 765-777.

[34] Ulmer, J. B.; Mason, P. W.; Geall, A.; Mandl, C. W. RNAbased vaccines. Vaccine 2012, 30, 4414-4418.

[35] Sasaki, S.; Takeshita, F.; Xin, K. Q.; Ishii, N.; Okuda, K. Adjuvant formulations and delivery systems for DNA vaccines. Methods 2003, 31, 243-254.

[36] Kojima, Y.; Xin, K. Q.; Ooki, T.; Hamajima, K.; Oikawa, T.; Shinoda, K.; Ozaki, T.; Hoshino, Y.; Jounai, N.; Nakazawa, M. et al. Adjuvant effect of multi-CpG motifs on an HIV-1 DNA vaccine. Vaccine 2002, 20, 2857-2865.

[37] Scheerlinck, J. P. Y. Genetic adjuvants for DNA vaccines. Vaccine 2001, 19, 2647-2656.

[38] Pascolo, S. Vaccination with messenger RNA. Methods Mol. Med. 2006, 127, 23-40.

[39] Guan, S.; Rosenecker, J. Nanotechnologies in delivery of mRNA therapeutics using nonviral vector-based delivery systems. Gene Ther. 2017, 24, 133-143.

[40] Pardi, N.; Hogan, M. J.; Porter, F. W.; Weissman, D. mRNA vaccines-A new era in vaccinology. Nat. Rev. Drug Discov. 2018, 17, 261-279.

[41] Thess, A.; Grund, S.; Mui, B. L.; Hope, M. J.; Baumhof, P.; Fotin-Mleczek, M.; Schlake, T. Sequence-engineered mRNA without chemical nucleoside modifications enables an effective protein therapy in large animals. Mol. Ther. 2015, 23, 1456-1464.

[42] Karikó, K.; Muramatsu, H.; Ludwig, J.; Weissman, D. Generating the optimal mRNA for therapy: HPLC purification eliminates immune activation and improves translation of nucleoside-modified, protein-encoding mRNA. Nucleic Acids Res. 2011, 39, e142.

[43] Tavernier, G.; Andries, O.; Demeester, J.; Sanders, N. N.; De Smedt, S. C.; Rejman, J. mRNA as gene therapeutic: How to control protein expression. J. Control. Release 2011, 150, 238-247.

[44] Frolov, I.; Hoffman, T. A.; Prágai, B. M.; Dryga, S. A.; 
Huang, H. V.; Schlesinger, S.; Rice, C. M. Alphavirus-based expression vectors: Strategies and applications. Proc. Natl. Acad. Sci. USA 1996, 93, 11371-11377.

[45] Brito, L. A.; Kommareddy, S.; Maione, D.; Uematsu, Y.; Giovani, C.; Scorza, F. B.; Otten, G. R.; Yu, D.; Mandl, C. W.; Mason, P. W. et al. Self-amplifying mRNA vaccines. Adv. Genet. 2015, 89, 179-233.

[46] Petsch, B.; Schnee, M.; Vogel, A. B.; Lange, E.; Hoffmann, B.; Voss, D.; Schlake, T.; Thess, A.; Kallen, K. J.; Stitz, L. et al. Protective efficacy of in vitro synthesized, specific mRNA vaccines against influenza A virus infection. Nat. Biotechnol. 2012, 30, 1210-1216.

[47] Richner, J. M.; Himansu, S.; Dowd, K. A.; Butler, S. L.; Salazar, V.; Fox, J. M.; Julander, J. G.; Tang, W. W.; Shresta, S.; Pierson, T. C. et al. Modified mRNA vaccines protect against Zika virus infection. Cell 2017, 168, 1114-1125.e10.

[48] Forde, G. M. Rapid-response vaccines - Does DNA offer a solution? Nat. Biotechnol. 2005, 23, 1059-1062.

[49] Pijlman, G. P.; Suhrbier, A.; Khromykh, A. A. Kunjin virus replicons: An RNA-based, non-cytopathic viral vector system for protein production, vaccine and gene therapy applications. Expert Opin. Biol. Ther. 2006, 6, 135-145.

[50] Saxena, S.; Sonwane, A. A.; Dahiya, S. S.; Patel, C. L.; Saini, M.; Rai, A.; Gupta, P. K. Induction of immune responses and protection in mice against rabies using a self-replicating RNA vaccine encoding rabies virus glycoprotein. Vet. Microbiol. 2009, 136, 36-44.

[51] Bourquin, C.; Schmidt, L.; Hornung, V.; Wurzenberger, C.; Anz, D.; Sandholzer, N.; Schreiber, S.; Voelkl, A.; Hartmann, G.; Endres, S. Immunostimulatory RNA oligonucleotides trigger an antigen-specific cytotoxic T-cell and IgG2a response. Blood 2007, 109, 2953-2960.

[52] Diebold, S. S.; Kaisho, T.; Hemmi, H.; Akira, S.; Sousa, C. R. E. Innate antiviral responses by means of TLR7-mediated recognition of single-stranded RNA. Science 2004, 303, 1529-1531.

[53] Van Lint, S.; Renmans, D.; Broos, K.; Dewitte, H.; Lentacker, I.; Heirman, C.; Breckpot, K.; Thielemans, K. The ReNAissanCe of mRNA-based cancer therapy. Expert Rev. Vaccines 2015, 14, 235-251.

[54] Schlake, T.; Thess, A.; Fotin-Mleczek, M.; Kallen, K. J. Developing mRNA-vaccine technologies. RNA Biol. 2012, 9, 1319-1330.

[55] Deering, R. P.; Kommareddy, S.; Ulmer, J. B.; Brito, L. A.; Geall, A. J. Nucleic acid vaccines: Prospects for non-viral delivery of mRNA vaccines. Expert Opin. Drug Deliv. 2014, $11,885-899$.

[56] Cho, N. H.; Cheong, T. C.; Min, J. H.; Wu, J. H.; Lee, S. J.; Kim, D.; Yang, J. S.; Kim, S.; Kim, Y. K.; Seong, S. Y. A multifunctional core-shell nanoparticle for dendritic cellbased cancer immunotherapy. Nat. Nanotechnol. 2011, 6, 675-682.

[57] Su, X. F.; Fricke, J.; Kavanagh, D. G.; Irvine, D. J. In vitro and in vivo mRNA delivery using lipid-enveloped $\mathrm{pH}$-responsive polymer nanoparticles. Mol. Pharmaceut. 2011, 8, 774-787.

[58] Rollier, C. S.; Reyes-Sandoval, A.; Cottingham, M. G.; Ewer, K.; Hill, A. V. S. Viral vectors as vaccine platforms: Deployment in sight. Curr. Opin. Immunol. 2011, 23, 377382.

[59] Harrop, R.; John, J.; Carroll, M. W. Recombinant viral vectors: Cancer vaccines. Adv. Drug Deliv. Rev. 2006, 58, 931-947.

[60] Nascimento, I. P.; Leite, L. C. C. Recombinant vaccines and the development of new vaccine strategies. Braz. J. Med. Biol. Res. 2012, 45, 1102-1111.

[61] Hollevoet, K.; Declerck, P. J. State of play and clinical prospects of antibody gene transfer. J. Transl. Med. 2017, $15,131$.

[62] Johanning, F. W.; Conry, R. M.; LoBuglio, A. F.; Wright, M.; Sumerel, L. A.; Pike, M. J.; Curiel, D. T. A sindbis virus mRNA polynucleotide vector achieves prolonged and high level heterologous gene expression in vivo. Nucleic Acids Res. 1995, 23, 1495-1501.

[63] Fotin-Mleczek, M.; Duchardt, K. M.; Lorenz, C.; Pfeiffer, R.; Ojkić-Zrna, S.; Probst, J.; Kallen, K. J. Messenger RNAbased vaccines with dual activity induce balanced TLR-7 dependent adaptive immune responses and provide antitumor activity. J. Immunother. 2011, 34, 1-15.

[64] Weide, B.; Pascolo, S.; Scheel, B.; Derhovanessian, E.; Pflugfelder, A.; Eigentler, T. K.; Pawelec, G.; Hoerr, I.; Rammensee, H. G.; Garbe, C. Direct injection of protamineprotected mRNA: Results of a phase $1 / 2$ vaccination trial in metastatic melanoma patients. J. Immunother. 2009, 32, 498-507.

[65] Islam, M. A.; Reesor, E. K. G.; Xu, Y. J.; Zope, H. R.; Zetter, B. R.; Shi, J. J. Biomaterials for mRNA delivery. Biomater. Sci. 2015, 3, 1519-1533.

[66] Phua, K. K. L.; Nair, S. K.; Leong, K. W. Messenger RNA (mRNA) nanoparticle tumour vaccination. Nanoscale 2014, 6, 7715-7729.

[67] Manolova, V.; Flace, A.; Bauer, M.; Schwarz, K.; Saudan, P.; Bachmann, M. F. Nanoparticles target distinct dendritic cell populations according to their size. Eur. J. Immunol. 2008, 38, 1404-1413.

[68] Liu, H. P.; Irvine, D. J. Guiding principles in the design of molecular bioconjugates for vaccine applications. Bioconjug. Chem. 2015, 26, 791-801.

[69] Apostolopoulos, V.; Barnes, N.; Pietersz, G. A.; McKenzie, I. F. C. Ex vivo targeting of the macrophage mannose 
receptor generates anti-tumor CTL responses. Vaccine $\mathbf{2 0 0 0}$ 18, 3174-3184.

[70] Gao, J. M.; Chen, P. M.; Singh, Y.; Zhang, X. P.; Szekely, Z.; Stein, S.; Sinko, P. J. Novel monodisperse PEGtide dendrons: Design, fabrication, and evaluation of mannose receptor-mediated macrophage targeting. Bioconjug. Chem. 2013, 24, 1332-1344.

[71] Macri, C.; Dumont, C.; Johnston, A. P. R.; Mintern, J. D. Targeting dendritic cells: A promising strategy to improve vaccine effectiveness. Clin. Transl. Immunol. 2016, 5, e66.

[72] Sahin, U.; Karikó, K.; Türeci, Ö. mRNA-based therapeuticsDeveloping a new class of drugs. Nat. Rev. Drug Discov. 2014, 13, 759-780.

[73] Kwon, H.; Kim, M.; Seo, Y.; Moon, Y. S.; Lee, H. J.; Lee, K.; Lee, H. Emergence of synthetic mRNA: In vitro synthesis of mRNA and its applications in regenerative medicine. Biomaterials 2018, 156, 172-193.

[74] Strenkowska, M.; Kowalska, J.; Lukaszewicz, M.; Zuberek, J.; Su, W.; Rhoads, R. E.; Darzynkiewicz, E.; Jemielity, J. Towards mRNA with superior translational activity: Synthesis and properties of ARCA tetraphosphates with single phosphorothioate modifications. New J. Chem. 2010, 34, 993-1007.

[75] Mockey, M.; Gonçalves, C.; Dupuy, F. P.; Lemoine, F. M.; Pichon, C.; Midoux, P. mRNA transfection of dendritic cells: Synergistic effect of ARCA mRNA capping with Poly(A) chains in cis and in trans for a high protein expression level. Biochem. Biophys. Res. Commun. 2006, 340, 1062-1068.

[76] Gerdil, C. The annual production cycle for influenza vaccine. Vaccine 2003, 21, 1776-1779.

[77] Kieny, M. P.; Costa, A.; Hombach, J.; Carrasco, P.; Pervikov, Y.; Salisbury, D.; Greco, M.; Gust, I.; LaForce, M.; FrancoParedes, C. et al. A global pandemic influenza vaccine action plan. Vaccine 2006, 24, 6367-6370.

[78] Geall, A. J.; Verma, A.; Otten, G. R.; Shaw, C. A.; Hekele, A.; Banerjee, K.; Cu, Y.; Beard, C. W.; Brito, L. A.; Krucker, T. et al. Nonviral delivery of self-amplifying RNA vaccines. Proc. Natl. Acad. Sci. USA 2012, 109, 14604-14609.

[79] Hekele, A.; Bertholet, S.; Archer, J.; Gibson, D. G.; Palladino, G.; Brito, L. A.; Otten, G. R.; Brazzoli, M.; Buccato, S.; Bonci, A. et al. Rapidly produced $\mathrm{SAM}^{\mathbb{B}}$ vaccine against $\mathrm{H} 7 \mathrm{~N} 9$ influenza is immunogenic in mice. Emerg. Microbes Infect. 2013, 2, e52.

[80] Semple, S. C.; Akinc, A.; Chen, J. X.; Sandhu, A. P.; Mui, B. L.; Cho, C. K.; Sah, D. W. Y.; Stebbing, D.; Crosley, E. J.; Yaworski, E. et al. Rational design of cationic lipids for siRNA delivery. Nat. Biotechnol. 2010, 28, 172-176.

[81] Whitehead, K. A.; Langer, R.; Anderson, D. G. Knocking down barriers: Advances in siRNA delivery. Nat. Rev. Drug
Discov. 2009, 8, 129-138.

[82] Brito, L. A.; Chan, M.; Shaw, C. A.; Hekele, A.; Carsillo, T.; Schaefer, M.; Archer, J.; Seubert, A.; Otten, G. R.; Beard, C. W. et al. A cationic nanoemulsion for the delivery of next-generation RNA vaccines. Mol. Ther. 2014, 22, 2118 2129.

[83] Podda, A. The adjuvanted influenza vaccines with novel adjuvants: Experience with the MF59-adjuvanted vaccine. Vaccine 2001, 19, 2673-2680.

[84] Podda, A.; Del Giudice, G. MF59-adjuvanted vaccines: Increased immunogenicity with an optimal safety profile. Expert Rev. Vaccines 2003, 2, 197-203.

[85] Urruticoechea, A.; Alemany, R.; Balart, J.; Villanueva, A.; Vinals, F.; Capella, G. Recent advances in cancer therapy: An overview. Curr. Pharm. Des. 2010, 16, 3-10.

[86] Huang, M.; Shen, A. J.; Ding, J.; Geng, M. Y. Molecularly targeted cancer therapy: Some lessons from the past decade. Trends Pharmacol. Sci. 2014, 35, 41-50.

[87] Connors, T. Anticancer drug development: The way forward. Oncologist 1996, 1, 180-181.

[88] DeVita, V. T.; Chu, E. A history of cancer chemotherapy. Cancer Res. 2008, 68, 8643-8653.

[89] Baudino, T. A. Targeted cancer therapy: The next generation of cancer treatment. Curr. Drug Discov. Technol. 2015, 12, 3-20.

[90] Ramirez, L. Y.; Huestis, S. E.; Yap, T. Y.; Zyzanski, S.; Drotar, D.; Kodish, E. Potential chemotherapy side effects: What do oncologists tell parents? Pediatr. Blood Cancer 2009, 52, 497-502.

[91] Sartore-Bianchi, A.; Martini, M.; Molinari, F.; Veronese, S.; Nichelatti, M.; Artale, S.; Di Nicolantonio, F.; Saletti, P.; De Dosso, S.; Mazzucchelli, L. et al. PIK3CA mutations in colorectal cancer are associated with clinical resistance to EGFR-targeted monoclonal antibodies. Cancer Res. 2009, 69, 1851-1857.

[92] Sharma, S. V.; Bell, D. W.; Settleman, J.; Haber, D. A. Epidermal growth factor receptor mutations in lung cancer. Nat. Rev. Cancer 2007, 7, 169-181.

[93] Siena, S.; Sartore-Bianchi, A.; Di Nicolantonio, F.; Balfour, J.; Bardelli, A. Biomarkers predicting clinical outcome of epidermal growth factor receptor-targeted therapy in metastatic colorectal cancer. J. Natl. Cancer Inst. 2009, 101, 1308-1324.

[94] Tsai, H. F.; Hsu, P. N. Cancer immunotherapy by targeting immune checkpoints: Mechanism of $\mathrm{T}$ cell dysfunction in cancer immunity and new therapeutic targets. J. Biomed. Sci. 2017, 24, 35.

[95] Tavares, A. B. M. L. A.; Neto, J. X. L.; Fulco, U. L.; Albuquerque, E. L. Inhibition of the checkpoint protein PD-1 by the therapeutic antibody pembrolizumab outlined 
by quantum chemistry. Sci. Rep. 2018, $8,1840$.

[96] Pardoll, D. M. The blockade of immune checkpoints in cancer immunotherapy. Nat. Rev. Cancer 2012, 12, 252-264.

[97] Dine, J.; Gordon, R.; Shames, Y.; Kasler, M. K.; BartonBurke, M. Immune checkpoint inhibitors: An innovation in immunotherapy for the treatment and management of patients with cancer. Asia Pac. J. Oncol. Nurs. 2017, 4, 127-135.

[98] Wada, S.; Jackson, C. M.; Yoshimura, K.; Yen, H. R.; Getnet, D.; Harris, T. J.; Goldberg, M. V.; Bruno, T. C.; Grosso, J. F.; Durham, N. et al. Sequencing CTLA-4 blockade with cell-based immunotherapy for prostate cancer. J. Transl. Med. 2013, 11, 89.

[99] Belcaid, Z.; Phallen, J. A.; Zeng, J.; See, A. P.; Mathios, D.; Gottschalk, C.; Nicholas, S.; Kellett, M.; Ruzevick, J.; Jackson, C. et al. Focal radiation therapy combined with 4-1BB activation and CTLA-4 blockade yields long-term survival and a protective antigen-specific memory response in a murine glioma model. PLoS One 2014, 9, e101764.

[100] Taggart, D.; Andreou, T.; Scott, K. J.; Williams, J.; Rippaus, N.; Brownlie, R. J.; Ilett, E. J.; Salmond, R. J.; Melcher, A.; Lorger, M. Anti-PD-1/anti-CTLA-4 efficacy in melanoma brain metastases depends on extracranial disease and augmentation of $\mathrm{CD}^{+} \mathrm{T}$ cell trafficking. Proc. Natl. Acad. Sci. USA 2018, 115, E1540-E1549.

[101] Lewis, K. E.; Selby, M. J.; Masters, G.; Valle, J.; Dito, G.; Curtis, W. R.; Garcia, R.; Mink, K. A.; Waggie, K. S.; Holdren, M. S. et al. Interleukin-21 combined with PD-1 or CTLA-4 blockade enhances antitumor immunity in mouse tumor models. Oncoimmunology 2018, 7, e1377873.

[102] Takeuchi, Y.; Tanemura, A.; Tada, Y.; Katayama, I.; Kumanogoh, A.; Nishikawa, H. Clinical response to PD-1 blockade correlates with a sub-fraction of peripheral central memory $\mathrm{CD}^{+} \mathrm{T}$ cells in patients with malignant melanoma. Int. Immunol. 2018, 30, 13-22.

[103] O'Neil, B. H.; Wallmark, J. M.; Lorente, D.; Elez, E.; Raimbourg, J.; Gomez-Roca, C.; Ejadi, S.; Piha-Paul, S. A.; Stein, M. N.; Razak, A. R. A. et al. Safety and antitumor activity of the anti-PD-1 antibody pembrolizumab in patients with advanced colorectal carcinoma. PLoS One 2017, 12, e0189848.

[104] Li, H.; Li, X. Q.; Liu, S.; Guo, L.; Zhang, B.; Zhang, J. B.; Ye, Q. H. Programmed cell death-1 (PD-1) checkpoint blockade in combination with a mammalian target of rapamycin inhibitor restrains hepatocellular carcinoma growth induced by hepatoma cell-intrinsic PD-1. Hepatology 2017, 66, 1920-1933.

[105] Huang, G. H.; Sun, X.; Liu, D. P.; Zhang, Y. F.; Zhang, B. X.; Xiao, G. D.; Li, X.; Gao, X.; Hu, C. H.; Wang, M. et al. The efficacy and safety of anti-PD-1/PD-L1 antibody therapy versus docetaxel for pretreated advanced NSCLC: A meta-analysis. Oncotarget 2018, 9, 4239-4248.

[106] Gong, J.; Chehrazi-Raffle, A.; Reddi, S.; Salgia, R. Development of PD-1 and PD-L1 inhibitors as a form of cancer immunotherapy: A comprehensive review of registration trials and future considerations. J. Immunother. Cancer 2018, 6, 8.

[107] Schlom, J. Therapeutic cancer vaccines: Current status and moving forward. J. Natl. Cancer Inst. 2012, 104, 599-613.

[108] Guo, C. Q.; Manjili, M. H.; Subjeck, J. R.; Sarkar, D.; Fisher, P. B.; Wang, X. Y. Therapeutic cancer vaccines: Past, present, and future. Adv. Cancer Res. 2013, 119, 421-475.

[109] Kim, R.; Emi, M.; Tanabe, K. Cancer immunoediting from immune surveillance to immune escape. Immunology 2007, 121, 1-14.

[110] Swann, J. B.; Smyth, M. J. Immune surveillance of tumors. J. Clin. Invest. 2007, 117, 1137-1146.

[111] Rice, J.; Ottensmeier, C. H.; Stevenson, F. K. DNA vaccines: Precision tools for activating effective immunity against cancer. Nat. Rev. Cancer 2008, 8, 108-120.

[112] Fotin-Mleczek, M.; Zanzinger, K.; Heidenreich, R.; Lorenz, C.; Thess, A.; Duchardt, K. M.; Kallen, K. J. Highly potent mRNA based cancer vaccines represent an attractive platform for combination therapies supporting an improved therapeutic effect. J. Gene Med. 2012, 14, 428-439.

[113] Bonehill, A.; Tuyaerts, S.; Van Nuffel, A. M.; Heirman, C.; Bos, T. J.; Fostier, K.; Neyns, B.; Thielemans, K. Enhancing the T-cell stimulatory capacity of human dendritic cells by co-electroporation with CD40L, CD70 and constitutively active TLR4 encoding mRNA. Mol. Ther. 2008, 16, 1170-1180.

[114] Kranz, L. M.; Diken, M.; Haas, H.; Kreiter, S.; Loquai, C.; Reuter, K. C.; Meng, M.; Fritz, D.; Vascotto, F.; Hefesha, H. et al. Systemic RNA delivery to dendritic cells exploits antiviral defence for cancer immunotherapy. Nature 2016, 534, 396-401.

[115] Thomas, A. M.; Santarsiero, L. M.; Lutz, E. R.; Armstrong, T. D.; Chen, Y. C.; Huang, L. Q.; Laheru, D. A.; Goggins, M.; Hruban, R. H.; Jaffee, E. M. Mesothelin-specific $\mathrm{CD}^{+} \mathrm{T}$ cell responses provide evidence of in vivo crosspriming by antigen-presenting cells in vaccinated pancreatic cancer patients. J. Exp. Med. 2004, 200, 297-306.

[116] Nair, S. K.; Snyder, D.; Rouse, B. T.; Gilboa, E. Regression of tumors in mice vaccinated with professional antigen-presenting cells pulsed with tumor extracts. Int. J. Cancer 1997, 70, 706-718.

[117] Anderson, C. F.; Lucas, M.; Gutierrez-Kobeh, L.; Field, A. E.; Mosser, D. M. T cell biasing by activated dendritic cells. J. Immunol. 2004, 173, 955-961. 
[118] Chauvin, C.; Josien, R. Dendritic cells as killers: Mechanistic aspects and potential roles. J. Immunol. 2008, 181, 11-16.

[119] Lehtonen, A.; Ahlfors, H.; Veckman, V.; Miettinen, M.; Lahesmaa, R.; Julkunen, I. Gene expression profiling during differentiation of human monocytes to macrophages or dendritic cells. J. Leukocyte Biol. 2007, 82, 710-720.

[120] Van Lint, S.; Goyvaerts, C.; Maenhout, S.; Goethals, L.; Disy, A.; Benteyn, D.; Pen, J.; Bonehill, A.; Heirman, C.; Breckpot, K. et al. Preclinical evaluation of TriMix and antigen mRNA-based antitumor therapy. Cancer Res. 2012, $72,1661-1671$

[121] Dudek, A. M.; Martin, S.; Garg, A. D.; Agostinis, P. Immature, semi-mature, and fully mature dendritic cells: Toward a DC-cancer cells interface that augments anticancer immunity. Front. Immunol. 2013, 4, 438.

[122] Albert, M. L.; Sauter, B.; Bhardwaj, N. Dendritic cells acquire antigen from apoptotic cells and induce class I-restricted CTLs. Nature 1998, 392, 86-89.

[123] Bennett, S. R. M.; Carbone, F. R.; Karamalis, F.; Miller, J. F. A. P.; Heath, W. R. Induction of a $\mathrm{CD} 8^{+}$cytotoxic $\mathrm{T}$ lymphocyte response by cross-priming requires cognate $\mathrm{CD}^{+}$T cell help. J. Exp. Med. 1997, 186, 65-70.

[124] Gilboa, E.; Vieweg, J. Cancer immunotherapy with mRNA-transfected dendritic cells. Immunol. Rev. 2004, 199, 251-263.

[125] Gilboa, E. DC-based cancer vaccines. J. Clin. Invest. 2007, 117, 1195-1203.

[126] Bachmann, M. F.; Jennings, G. T. Vaccine delivery: A matter of size, geometry, kinetics and molecular patterns. Nat. Rev. Immunol. 2010, 10, 787-796.

[127] Reddy, S. T.; van der Vlies, A. J.; Simeoni, E.; Angeli, V.; Randolph, G. J.; O'Neill, C. P.; Lee, L. K.; Swartz, M. A.; Hubbell, J. A. Exploiting lymphatic transport and complement activation in nanoparticle vaccines. Nat. Biotechnol. 2007, 25, 1159-1164.

[128] Swartz, M. A.; Berk, D. A.; Jain, R. K. Transport in lymphatic capillaries. I. Macroscopic measurements using residence time distribution theory. Am. J. Physiol. 1996, 270, H324-H329.

[129] Kyte, J. A.; Aamdal, S.; Dueland, S.; Sæbøe-Larsen, S.; Inderberg, E. M.; Madsbu, U. E.; Skovlund, E.; Gaudernack, G.; Kvalheim, G. Immune response and long-term clinical outcome in advanced melanoma patients vaccinated with
tumor-mRNA-transfected dendritic cells. Oncoimmunology 2016, 5, e1232237.

[130] Kallen, K. J.; Heidenreich, R.; Schnee, M.; Petsch, B.; Schlake, T.; Thess, A.; Baumhof, P.; Scheel, B.; Koch, S. D.; Fotin-Mleczek, M. A novel, disruptive vaccination technology: Self-adjuvanted RNActive (R) vaccines. Hum. Vaccin. Immunother. 2013, 9, 2263-2276.

[131] Sebastian, M.; Papachristofilou, A.; Weiss, C.; Früh, M.; Cathomas, R.; Hilbe, W.; Wehler, T.; Rippin, G.; Koch, S. D.; Scheel, B. et al. Phase Ib study evaluating a selfadjuvanted mRNA cancer vaccine (RNActive ${ }^{\circledR}$ ) combined with local radiation as consolidation and maintenance treatment for patients with stage IV non-small cell lung cancer. BMC Cancer 2014, 14, 748.

[132] Phua, K. K. L. Towards targeted delivery systems: Ligand conjugation strategies for mrna nanoparticle tumor vaccines. J. Immunol. Res. 2015, 2015, Article ID 680620.

[133] Boczkowski, D.; Nair, S. K.; Snyder, D.; Gilboa, E. Dendritic cells pulsed with RNA are potent antigen-presenting cells in vitro and in vivo. J. Exp. Med. 1996, 184, 465-472.

[134] Perche, F.; Benvegnu, T.; Berchel, M.; Lebegue, L.; Pichon, C.; Jaffrès, P. A.; Midoux, P. Enhancement of dendritic cells transfection in vivo and of vaccination against B16F10 melanoma with mannosylated histidylated lipopolyplexes loaded with tumor antigen messenger RNA. Nanomedicine 2011, 7, 445-453.

[135] Zheng, X. F.; Vladau, C.; Zhang, X. S.; Suzuki, M.; Ichim, T. E.; Zhang, Z. X.; Li, M.; Carrier, E.; Garcia, B.; Jevnikar, A. M. et al. A novel in vivo siRNA delivery system specifically targeting dendritic cells and silencing CD40 genes for immunomodulation. Blood 2009, 113, 2646-2654.

[136] Singh, A.; Suri, S.; Roy, K. In-situ crosslinking hydrogels for combinatorial delivery of chemokines and siRNA-DNA carrying microparticles to dendritic cells. Biomaterials 2009, 30, 5187-5200.

[137] Sebastian, M.; von Boehmer, L.; Zippelius, A.; Mayer, F.; Reck, M.; Atanackovic, D.; Thomas, M.; Schneller, F.; Stoehlmacher, J.; Goekkurt, E. et al. Messenger RNA vaccination in NSCLC: Findings from a phase I/IIa clinical trial. J. Clin. Oncol. 2011, 29, 2584.

[138] Weiner, L. M.; Surana, R.; Wang, S. Z. Monoclonal antibodies: Versatile platforms for cancer immunotherapy. Nat. Rev. Immunol. 2010, 10, 317-327. 